\title{
Effects of Amino-Acid Substitutions in the Brome mosaic virus Capsid Protein on RNA Encapsidation
}

\author{
Masarapu Hema, ${ }^{1}$ Ayaluru Murali, ${ }^{1}$ Peng Ni, ${ }^{1}$ Robert C. Vaughan, ${ }^{1}$ Koki Fujisaki, ${ }^{1}$ Irina Tsvetkova, ${ }^{2}$ \\ Bogdan Dragnea, ${ }^{2}$ and C. Cheng Kao ${ }^{1}$ \\ ${ }^{1}$ Department of Molecular and Cellular Biochemistry and ${ }^{2}$ Department of Chemistry, Indiana University, Bloomington, \\ Indiana 47405, U.S.A.
}

Submitted 21 May 2010. Accepted 21 June 2010.

\begin{abstract}
Brome mosaic virus (BMV) packages its genomic RNAs (RNA1, RNA2, and RNA3) and subgenomic RNA4 into three different particles. However, since the RNAs in the virions have distinct lengths and electrostatic charges, we hypothesize that subsets of the virions should have distinct properties. A glutamine to cysteine substitution at position 120 of the capsid protein $(\mathrm{CP})$ was found to result in a mutant virus named QC that exhibited a dramatically altered ratio of the RNAs in virions. RNA2 was far more abundant than the other RNAs, although the ratios could be affected by the host plant species. RNAs with the QC mutation were competent for replication early in the infection, suggesting that they were either selectively packaged or degraded after packaging. In support of the latter idea, low concentrations of truncated RNA1 that co-migrated with RNA2 were found in the QC virions. Spectroscopic analysis and peptide fingerprinting experiments showed that the $\mathrm{QC}$ virus capsid interacted with the encapsidated RNAs differently than did the wild type. Furthermore, wild-type BMV RNA1 was found to be more susceptible to nuclease digestion relative to RNA2 as a function of the buffer pH. Other BMV capsid mutants also had altered ratios of packaged RNAs.
\end{abstract}

Brome mosaic virus (BMV), a member of the Bromoviridae family of plant viruses, has served as a model system for the infection of nonenveloped, multipartite, positive-strand RNA viruses (Kao and Sivakumaran 2000; Noueiry and Ahlquist 2003). The BMV genome consists of three capped, messengersense, genomic RNAs, designated RNA1, RNA2, and RNA3. Monocistronic RNA1 encodes the multifunctional protein 1a that transports BMV RNAs and replication-associated proteins to the site of RNA replication (Ahola and Ahlquist 1999; Chen et al. 2001; Diez et al. 2000; Schwartz et al. 2004; Sullivan and Ahlquist 1999). RNA2 encodes protein 2a, the RNA-dependent RNA polymerase that is the catalytic core of the BMV replicase (Kao and Sivakumaran 2000). RNA3 is a dicistronic RNA that encodes the movement protein (MP) required for

Corresponding author: C. Cheng Kao; Telephone: +1.812 .855 .7583 ; Fax: +1.812.856.5710; E-mail: ckao@indiana.edu

* The $\boldsymbol{e}$-Xtra logo stands for "electronic extra" and indicates that three supplementary figures and one supplementary table are published online. spread of the virus from the infected cell and the capsid protein (CP), which encapsidates BMV RNAs. Although MP is directly translated from the genomic RNA3, CP is translated from a subgenomic RNA (RNA4) transcribed by internal initiation from the minus-strand copy of RNA3 (Miller et al. 1985; Siegel et al. 1997). The BMV genomic RNAs are maintained in a specific ratio, in which $\mathrm{RNA} 1<\mathrm{RNA} 2<\mathrm{RNA} 3<\mathrm{RNA} 4$ (Marsh et al. 1991), and they are packaged in $T=3$ icosahedral particles (Lucas et al. 2002). Genomic RNA1 and RNA2 are encapsulated into separate viral particles, while RNA3 is co-packaged with subgenomic RNA4 (Annamalai and Rao 2007; Rao 2006).

Successful infection requires all three BMV RNAs to be in the same cell. Packaging of the RNAs into separate particles could allow for the reassortment of the BMV genome but requires proper coordination of the viral RNAs and their activities. The BMV CP is well positioned to be such a coordinator, since it accompanies the RNAs from the start to the end of an infection cycle. Consistent with its multifunctional role in infection, the $\mathrm{CP}$ can selectively bind the motif required for RNA replication (Zhu et al. 2007), regulate the translation of BMV RNA1 and RNA2 by binding to an RNA motif named the B box (Yi et al. 2009a and b), and selectively encapsidate the BMV RNAs.

One property shared between several icosahedral viruses is that they can expand and contract with changes in the buffer pH levels (Chen et al. 2006; Hiebert and Bancroft 1969; Pfeiffer and Hirth 1974; Speir et al. 2006). The latter feature has been used to generate gate-access chambers that can perform chemical reactions (Douglas and Young 1998; Fulton et al. 2009). Virus capsids thus represent a class of biomaterial suitable for molecular engineering that will have biotechnology applications (Jennings and Bachmann 2008). The BMV $\mathrm{CP}$ has also been gaining interest as a nanocage that can encapsulate foreign materials, such as functionalized nanogold and quantum dots (Chen et al. 2006; Dixit et al. 2006; Sun et al. 2007).

We have identified a class of mutant virions that have altered ratios of the four BMV RNAs. Virions with a glutamine to cysteine change at residue 120 were characterized in detail and found to have a nearly normal abundance of RNA2 but decreased amounts of the other BMV RNAs. Some RNA1 was truncated to the length of RNA2. This work seeks to understand the defect in this mutant. Understanding how the viral particles encapsidate the RNAs should be informative for the regulation of BMV infection as well as improve the ability to manipulate virus-like particles that contain foreign materials. 


\section{RESULTS}

Cysteine substitutions in the BMV capsid.

The CP of BMV (Russian strain) has only one cysteine, $\mathrm{C} 107$, which is buried within the globular domain. We sought to allow the covalent attachment of cargos to BMV by placing either one or two cysteines in adjacent capsid subunits. Viruses were made with the cysteine substitutions at Q120 (to be named QC), V168 (to be named VC), and at both positions (to be named DM). The BMV capsid subunits are arranged in pentamers and hexamers based on a $T=3$ BMV crystal structure that was solved to $3.4 \AA$ (Lucas et al. 2002). The locations of the substitutions as well as $\mathrm{C} 107$ in the pentamers and hexamers are shown in Figure 1A. The orientations of the side chains in two subunits of a hexamer are shown in Figure 1B. The distances between the alpha carbons of these residues in the subunits are approximately 6.1 to $6.4 \AA$ (Supplementary Fig. S1).

Production of the mutant virions used Nicotiana benthamiana plants infiltrated with a mixture of three recombinant Agrobacterium cultures to express the three BMV RNAs. Multiple T-
DNAs can be integrated into the host chromosome to allow manipulation of the BMV genome by adjusting the presence and concentration of the inoculum. BMV RNAs launched by Agrobacterium T-DNA will replicate in a manner similar to a normal BMV infection (Gopinath et al. 2005).

The mutations resulted in different levels of virion production. In $100 \mathrm{~g}$ of freshly harvested $N$. benthamiana leaves, we routinely obtain 12 to $15 \mathrm{mg}$ of CsCl-purified virions. The $\mathrm{VC}$ virions produced 8 to $10 \mathrm{mg}$ of purified virus in more than three preparations. The QC and the DM mutant had final yields of 1 to $1.5 \mathrm{mg}$ and 0.5 to $0.7 \mathrm{mg}$, respectively, in more than five preparations. Despite the differences in yields, reducing sodium dodecyl sulfate-polyacrylamide gel electrophoresis (SDS-PAGE) of the purified virions adjusted to similar protein concentrations revealed the expected capsid monomers of the expected electrophoretic mobilities (Fig. 2A). Electrospray analysis of the capsids dissociated from virions showed that the masses were within $1.5 \mathrm{Da}$ of the expected masses, and there were no obvious reversions back to the wild type (WT) (Supplementary Fig. S2).
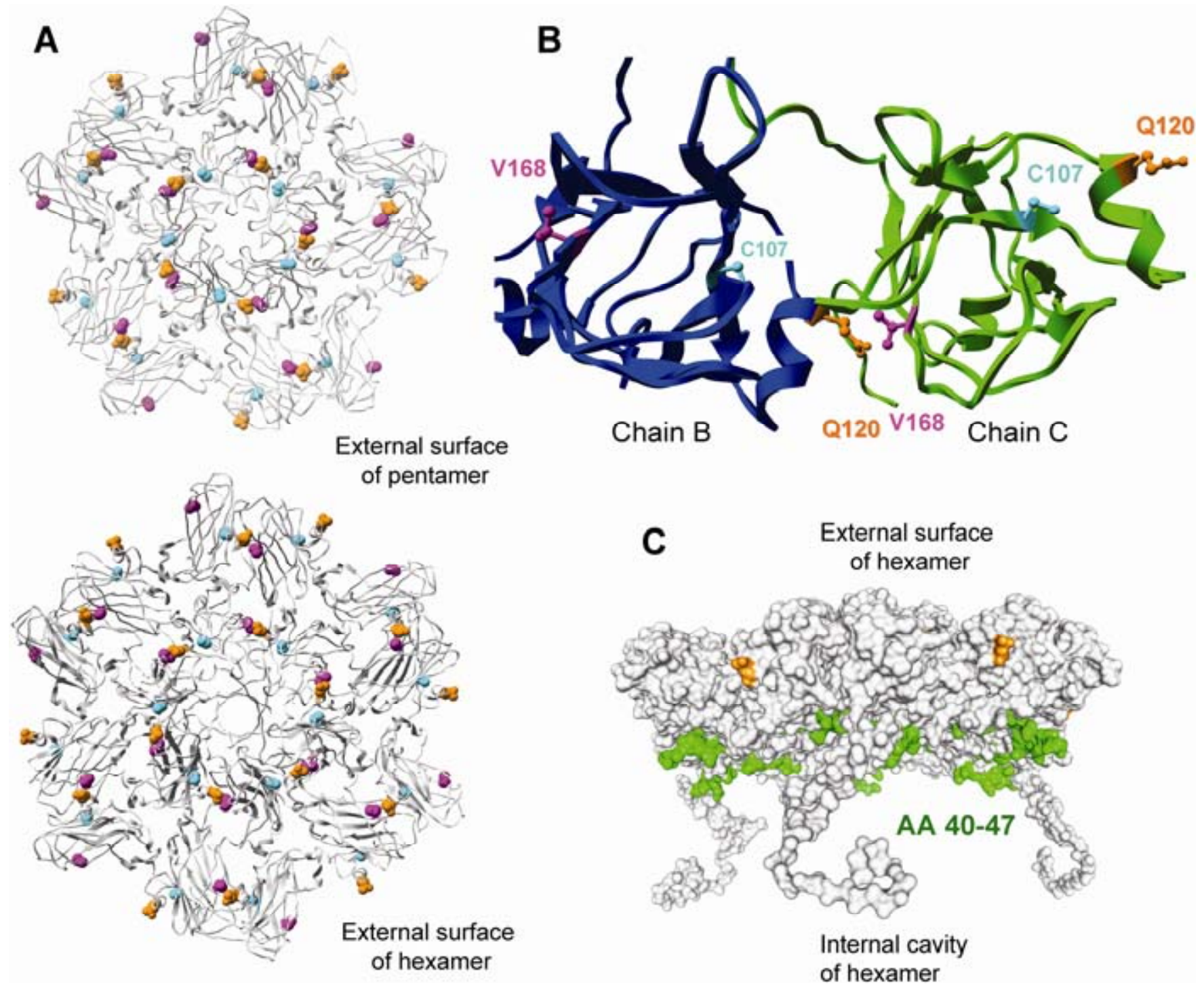

Fig. 1. Cysteine substitutions in the Brome mosaic virus (BMV) capsid protein. A, A representation of a central hexameric and pentameric capsomere along with a ring of interacting capsid subunits. The locations of the two mutations Q120C (orange) and V168C (magenta) are highlighted along with the C107 (sky blue) that is not predicted to participate in intra- or inter-subunit interactions. B, A closeup view of the orientation of the residues normally at positions 107, 120, and 168. C, The locations of the Q120C substitution (orange) relative to residues 40 to 47 (green) that were previously shown by Calhoun and associates (2007) to impact RNA packaging. The hexameric capsid is shown in the side view. We note that not all of the N-terminal tails were seen in the crystal structure of Lucas and associates (2002). 
To qualitatively examine whether virion RNAs were within the different viruses, $10 \mu \mathrm{g}$ of each of four virion preparations were analyzed by native agarose gel electrophoresis stained with ethidium bromide (Fig. 2B). Similar amounts of stained materials were observed in the QC and VC samples, although the DM samples had reduced levels of RNA. The QC and DM particles also exhibited altered electrophoretic mobilities, including materials trapped at the bottom of the loading wells (Fig. 2B). These results suggest that despite the reduced yield of virions, the virions contain significant amounts of virionassociated RNAs.

The RNAs from the virions were extracted and analyzed. The WT and VC virions had similar ratios of the four BMV
RNAs (Fig. 2C). Interestingly, QC had no detectable RNA1, an abundance of RNA2, an additional RNA band below the position of RNA2 (indicated by the asterisk), and reduced RNA3 and RNA4 (Fig. 2C). There is also a slight increase in the smear that could represent degraded RNAs in the QC preparation (Fig. 2C, lane 3). This biased distribution of QC vRNAs was observed in every one of more than six QC preparations. Two independent preparations of the DM virions had ratios of RNAs similar to QC with relatively lower RNA concentrations. Since DM and QC share the Q120C substitution, a cysteine at position 120 of the capsid protein is responsible for the preferential packing of BMV RNA2. We seek to better understand this defect, since BMV RNAs are normally packaged with
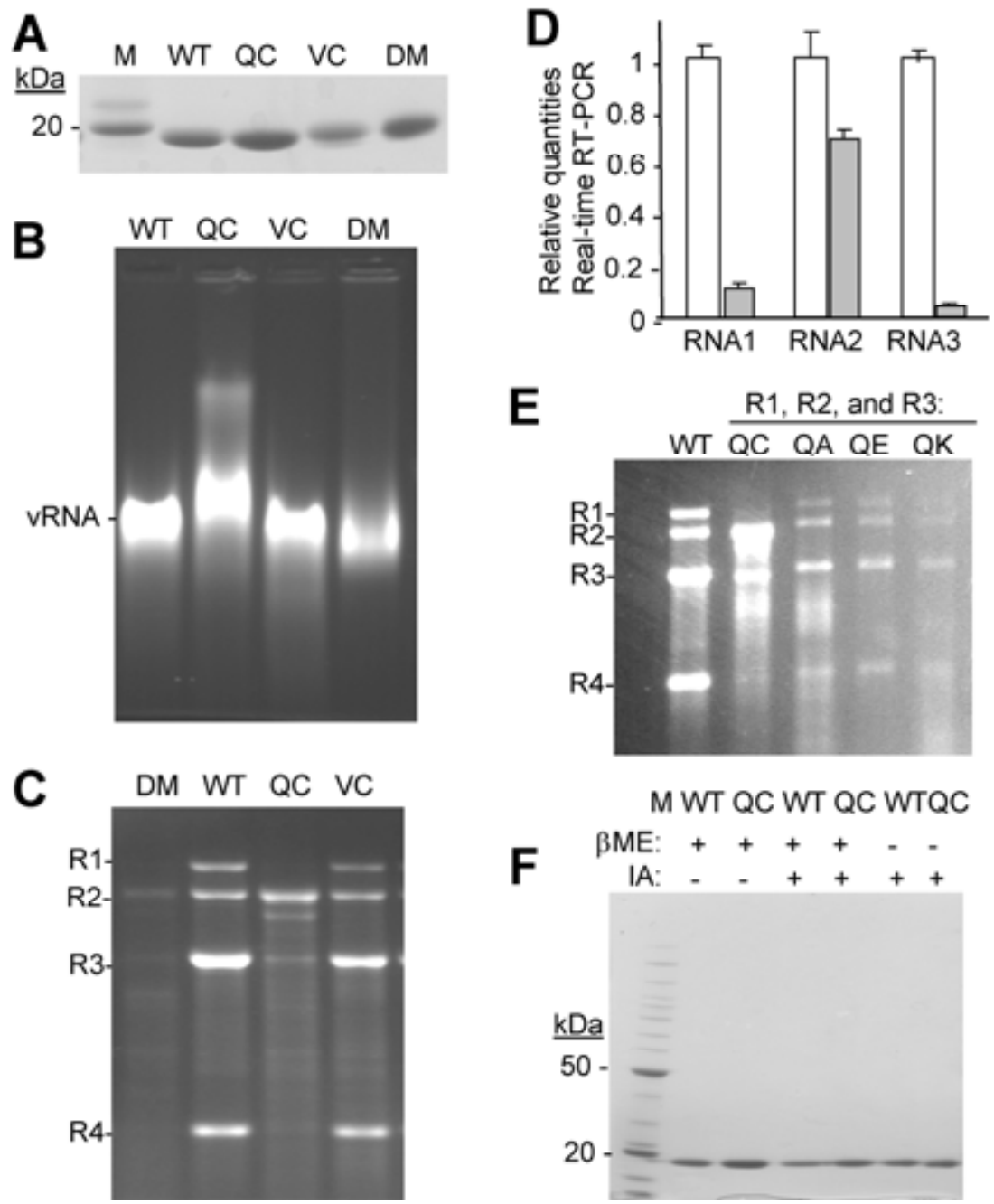

Fig. 2. Characterization of mutant Brome mosaic virus (BMV) virions. A, Capsid proteins from purified wild-type (WT) and mutant virions from Nicotiana benthamiana, as seen from reduced sodium dodecyl sulfate-polyacrylamide gel electrophoresis (SDS-PAGE) for which the capsids have been normalized to the same concentration. The image shows that the proteins are not grossly different in their electrophoretic mobilities and confirm the masses of the capsid subunits and that no obvious reversions or secondary changes to the virions were analyzed by electrospray mass spectrometry. $\mathrm{M}=$ molecular weight standard, WT $=$ wild type, $\mathrm{QC}=\mathrm{Q} 120 \mathrm{C}$ substitution mutant, $\mathrm{VC}=\mathrm{V} 168 \mathrm{C}$ substitution mutant, and $\mathrm{DM}=$ double mutant. $\mathbf{B}, \mathrm{A}$ qualitative examination of the RNAs associated with CsCl-purified WT and mutant BMV particles. Particles $(10 \mu \mathrm{g})$ were electrophoresed in a $0.8 \%$ nondenaturing agarose gel that can separate whole virions, and the gel was subsequently stained with ethidium bromide. C, Relative yields of the virion RNAs from $N$. benthamiana. The gel image contains ethidium bromide-stained RNAs from virions enriched by sucrose density gradients in which supernatant of plant extracts containing virions were loaded onto a sucrose cushion ( $10 \%$ sucrose, $50 \mathrm{mM} \mathrm{NaOAc} \mathrm{[pH} \mathrm{4.5]} \mathrm{and} 10 \mathrm{mM} \mathrm{MgOAc})$ and centrifuged at $135,000 \times g$ for $3 \mathrm{~h}$. The pellet was then extracted for RNA that were electrophoresed in a $1 \%$ agarose gel. Each sample of RNA was loaded at $1 \mu \mathrm{g}$ per lane to allow visualization of the relative amounts of the four BMV RNAs. D, Quantitative reverse transcription-polymerase chain reaction analysis of the three genomic RNAs in the WT BMV (white bars) and the QC mutant (gray bars). Means and standard errors from three independent preparations of virion-associated RNA used for the quantitative analyses are shown. E, Effects of other amino-acid substitutions at capsid residue 120 on BMV genomic RNA encapsidation. The RNAs used were purified from virions isolated 7 days after agroinfiltration. BMV RNA1, RNA2, and either the WT or the mutant RNA3 loaded in the gel are as indicated above the gel image. The virions were extracted for total RNA after sedimentation through a sucrose density cushion and were visualized after agarose gel electrophoresis and staining with ethidium bromide. F, Effects of the reducing and nonreducing conditions on BMV capsids to examine for crosslinking between subunits. The samples were mock treated or treated with $5 \mathrm{mM}$ iodoacetamide (IA) for $20 \mathrm{~min}$ at room temperature and were treated with protein sample buffers with and without $\beta$-mercaptoethonol ( $\beta$-ME), were loaded on to a 4 to $12 \%$ SDS-PAGE gel, and were stained with Coomassie blue. 
specific ratios despite no apparent interactions between the virions or the RNAs; understanding the selective packaging of a portion of the genome or a loss of RNA should impact the infection process.

To check infectivity, purified WT, VC, and QC virions were reinoculated into naïve plants. The $\mathrm{WT}$ and $\mathrm{VC}$ virions could infect $N$. benthamiana plants and spread systemically, but the QC mutant was defective for infection.

To quantify the RNAs within the QC virions, reverse transcription-polymerase chain reaction (RT-PCR) was used to amplify the RNAs from WT and QC virions, using real-time PCR (Fig. 2D). Three sets of primer pairs were used to generate an approximately 200-bp cDNA internal to each of the three BMV RNAs. Since different primer pairs are used for each BMV RNA, the results from the WT virion were normalized to $100 \%$. However, in the QC virion, the specific cDNAs for RNA1 and RNA3 were less than $15 \%$ of the amount of a comparable concentration of WT particles. The signal from RNA2 was at more than $65 \%$ of the level of WT BMV (Fig. 2D). A complete cDNA from RNA2 was generated by RTPCR, and the resultant cDNA from the QC RNA2 virion was determined to be WT (data not shown).

We examined whether other residues at position 120 of the $\mathrm{CP}$ would also alter distribution of RNAs. Site-directed mutagenesis was used to place an Ala, Glu, or Lys at position 120 in the context of BMV RNA3. When infiltrated into $N$. benthamiana along with WT RNA1 and RNA2, the three new mutants produced lower abundances of virus particles relative to WT BMV, but the encapsidated vRNAs had all four RNAs at ratios that are similar to that of the WT BMV (Fig. 2E). The highly unusual ratios of BMV genomic RNAs are thus specifically associated with a QC substitution.

Since pairs of cysteine residues can form crosslinks in oxidizing environments, we wanted to determine whether the cysteine at position 120 is participating in a disulfide bond formation in a nonreducing gel. The presence or absence of $\beta$ mercaptoethonol did not result in the detection of crosslinked products (Fig. 2F). This result is expected, since the molecular distances between cysteines in the virion are not conducive to disulfide bond formation. In addition, in another mutant BMV in which cysteines were place in adjacent capsid subunits, disulfide bonds were formed under the identical conditions used to analyze the QC mutant (data not shown).

\section{Models for the defect in QC.}

Several possible scenarios exist for the defect in the QC mutant. First, given that the CP can regulate BMV gene expression (Gopinath et al. 2005; Yi et al. 2009a; Zhu et al. 2007), the QC mutation could confer a defect in the selective replication of BMV RNAs. Second, the QC mutant is defective for encapsidation of BMV RNA1 and RNAs 3 and 4, with only a minor defect in the encapsidation of RNA2. Third, the QC substitution may be defective in maintaining the stability of BMV RNA1 and RNAs 3 and 4 after encapsidation. The third model would suggest that the encapsidated RNAs could affect virion stability.

Calhoun and associates (2007) reported that a deletion of residues 40 to 47 of the CP that projects into the internal cavity of the virion was defective in the packaging of one or more of the BMV RNAs. The location of the Q120C mutation is at the junction of two subunits near to outer surface of the BMV virion, while residues 40 to 47 were located in the internal cavity of the virions (Fig. 1C). The differences in the locations and nature of the mutants (an amino-acid substitution at position 120 at the interface of capsid subunits versus deletion of residues 40 and 47 in the internal cavity) suggest that the mechanisms are different for the altered ratios for these two mutants.

\section{Replication of the QC mutant.}

To examine whether the QC mutation had a replication defect, we harvested total RNAs 2 and 4 days after agroinfiltration into $N$. benthamiana, and samples were probed to detect the conserved $3^{\prime}$ untranslated region (UTR) of the BMV RNAs. RNA1 and RNA3 were present in the samples with the QC virus 2 days after infiltration (Fig. 3A). There were some signals shorter than RNA4 that are likely to be truncated BMV RNAs. However, by 4 and 6 days after infiltration, the levels of all of the RNAs were reduced, with more notable relative decrease in the abundances of RNA1 and RNA3 (Fig. 3A and data not shown). A second independent set of results from 2 and 5 days after infiltration revealed similar trends (Fig. 3A, lower panel). The presence of RNA1 and RNA3 at an early timepoint suggests that a defect in RNA synthesis is not the primary reason for the altered RNA distribution in the QC virion.

To examine whether the QC virions from protoplasts had a defect in virion RNA accumulation, aliquots of protoplasts from $30 \mathrm{~h}$ after transfection were lysed and the materials passed through a sucrose density cushion. The pellet was extracted for RNA and was subjected to Northern and Western blot analysis. The Western blots showed a decrease in the amount of the CP from the QC mutant in comparison with the WT, consistent with a defect in the recovery of the virions from the QC mutants in $N$. benthamiana (Fig. 3B). The Northern blot results showed a reduction in the amount of RNA1 and RNA4 (Fig. $3 B)$. We did not pursue the differences in the amounts of virion-associated BMV RNA4 in barley protoplasts and N. benthamiana, but the results in the barley protoplasts confirm that the QC mutation did not affect BMV RNA replication. Together with the results from $N$. benthamiana (Fig. 3A), these results suggest that the primary defect associated with the QC mutation is not at the level of BMV gene expression. Instead, the defect for the QC mutant likely exists in the selective packaging or selective degradation of the virion RNAs.

\section{Characterization of the QC virion RNAs.}

To distinguish whether the QC virion had a defect in RNA packaging or allowed selective RNA degradation, we examined whether RNA1 could be truncated in the QC preparation. A 45-nt oligonucleotide that will recognize a region within the 1a open reading frame (ORF) was used to probe the QC vRNAs (Fig. 4A). This probe detected WT RNA1 but not WT RNA2, demonstrating that it can distinguish the two RNAs. The probe recognized RNA1 at the location of RNA2 in four independently prepared QC vRNA preparations, suggesting that truncated RNA1 is present and co-migrates with RNA2 (Fig. 4A). The abundances of the truncated RNA1 did not correlate with the intensity of the ethidium bromide-stained band (Fig. 4A). Furthermore, the appearance of a smear in association with RNA1, suggests that it was cut at different sites. A fifth preparation of the QC virions purified over a cesium chloride density gradient and probed with an oligonucleotide that recognized the $3^{\prime}$ end of the 1a ORF revealed the same result (Fig. 4B). Altogether, these results show that RNA1 is much reduced in abundance, but whatever RNA1 was retained by the QC virion is truncated to approximately the length of RNA2.

Are the truncated RNA1 molecules in the QC vRNA preferentially cleaved in select regions? Five probes that bind sequences spanning the length of RNA1 were used to address this question (Fig. 4C). We did not use a probe targeting the $3^{\prime}$ UTR, since it would have detected all of the highly conserved 3' UTR in BMV RNAs. In two independently prepared QC vRNA samples tested, probes $B$ to $E$, which recognized the RNA1 ORF, recognize the truncated RNA1 better than did probe A when the signals were compared with the WT RNA1 present in the same blot (Fig. 4D, bottom). These results sug- 
gest that the 5' UTR of RNA1 is preferentially lost in the RNAs retained by the QC virions.

\section{Mapping of the capsid interaction with RNAs in QC virions.}

The altered RNA ratio exhibited by the QC virion suggests that interaction with the capsid will likely be affected by the QC mutation. To qualitatively examine this, purified WT and QC virions were examined for differences in trypsin susceptibility. Both virions were adjusted to the same protein concentration and were treated over a course of time. Within $15 \mathrm{~min}$. of exposure to trypsin, additional bands were revealed in the QC but not in the WT virions (Fig. 5A).

To better map the altered capsid-RNA interaction, we used a reversible crosslinking, RNA purification, and peptide fingerprinting analysis (named RCAP) that we had used to examine changes in capsid-RNA contact and the interaction between several RNA-binding proteins (Kim et al. 2005; Ranjith Kumar et al. 2009; Yi et al. 2009b). Briefly, formaldehyde was used to crosslink proteins to RNAs, followed by extensive treatment with trypin to generate peptide fragments. The RNA was then selectively precipitated with $\mathrm{LiCl}$ and the formaldehyde crosslinks were reversed by heating in an aqueous solution at $70^{\circ} \mathrm{C}$. The peptides were then purified and concentrated for matrixassisted laser desorption ionization-time of flight (MALDI-
TOF) analysis. The RNAs associated with the WT and the QC virions had significant signal from peptides that matched a theoretical digest of the $\mathrm{CP}$ in comparison with samples not treated with formaldehyde (Supplementary Fig. S3). The locations of the peptides on schematics of the WT and QC BMV capsid proteins are shown in Figure 5B. While both the WT and the QC peptides from the $\mathrm{N}$-terminal residues 2 to 44 were found (the $\mathrm{N}$-terminal residue of the BMV capsid is absent in the mature protein [Yi et al. 2009b]), significantly more peptides from the $\mathrm{N}$-terminal tail were identified in the QC virus. In addition, peptides spanning residues 65 to 84 and 89 to 103 were identified with the QC capsid but not with the WT. Also, the sequence encompassing Q120 was found to be co-precipitated with the WT but not the QC mutants (Fig. 5B). Finally, residues 166 to the Cterminus were identified only in the WT capsid. Summaries of the locations of the peptides within a monomer of the capsid are shown in Figure 5C. When mapped to the WT virion, the contacts between the inner cavity of the virion and the RNAs are significantly different (Fig. 5D). Significant conformational changes in the viral particles must take place to account for the observed differences in capsid-RNA interactions.

\section{Spectroscopic examination of purified QC virions.}

We used differential scanning fluorimetry (DSF) of whole virions to determine further the properties of the virions as a
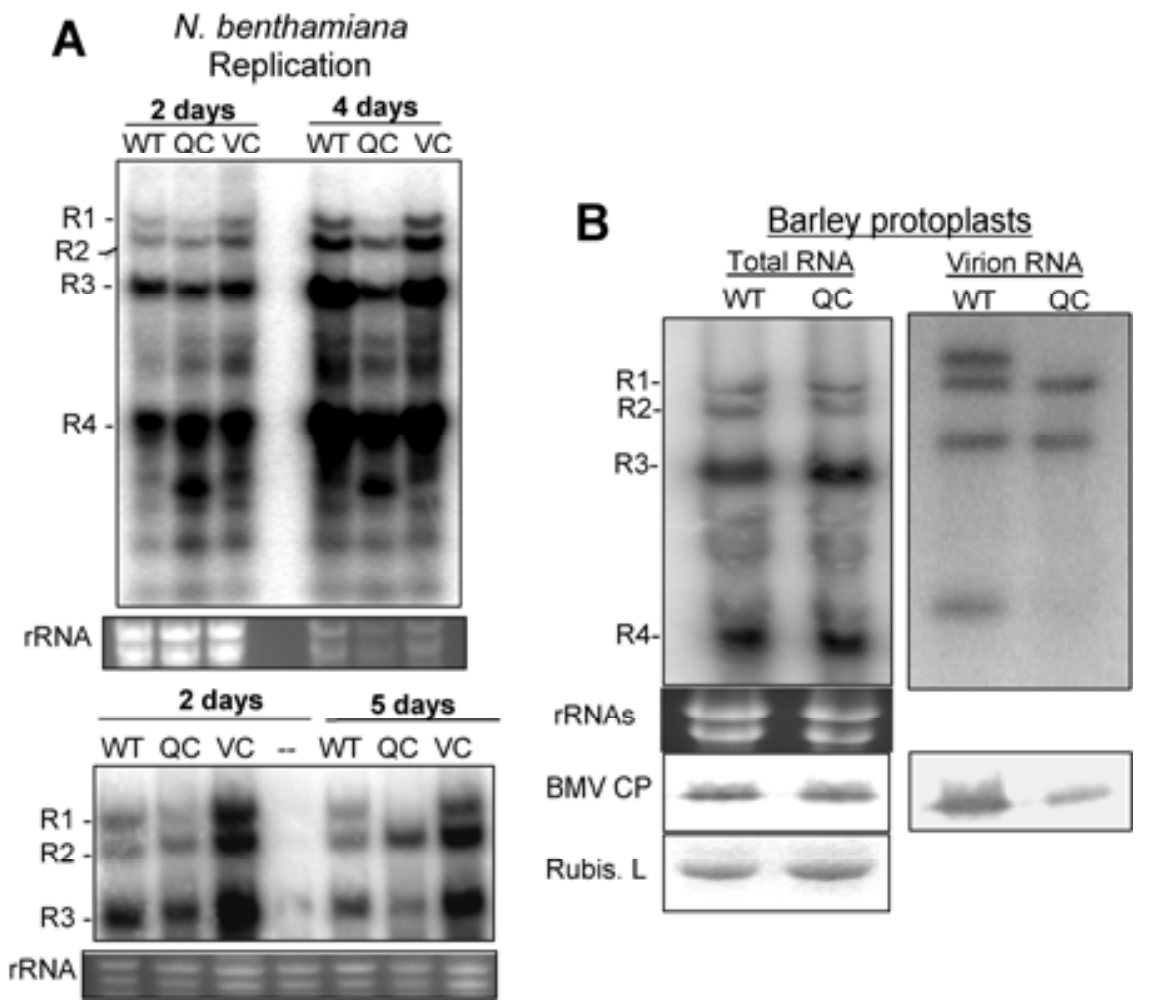

Fig. 3. Total RNA accumulation in the wild-type (WT) QC (Q120C substitution mutant)-infected plants. A, Brome mosaic virus (BMV) RNA replication products produced in Nicotiana benthamiana. The gel images were taken from Northern blots of independently prepared samples probed to detect the common 3' untranslated regions (UTR) of the BMV RNAs. The total RNAs were collected on the indicated number of days after Agrobacterium infiltration. The upper gel image contained $10 \mu \mathrm{g}$ of total RNA for the samples collected 2 days after agroinfiltration and $5 \mu \mathrm{g}$ of total RNA was loaded for the samples taken at 4 days. The bottom gel image contained RNAs from an independent experiment in which the RNAs were collected at 2 and 5 days after agroinfiltration. The identities of the RNAs are labeled to the right of the autoradiogram. The loading controls consist of a slice of the image from an ethidium bromide-stained agarose gel containing cellular rRNAs used to generate the Northern blot. B, Replication of transfected BMV RNAs in barley protoplasts. The autoradiogram image (left) is from samples transfected for $20 \mathrm{~h}$ and probed to detect the BMV $3^{\prime}$ UTR. The expression of the WT and QC Capsid proteins (CP) (left bottom panel) from barley protoplasts was detected by Western blots of equal aliquots of the protoplast lysate using a rabbit polyclonal antiserum specific to the BMV CP. The membrane for the Western blot was stained with Coomassie blue, and the large Rubisco subunit is shown as a loading control (Rub. L). The panel to the right shows the RNAs associated with the BMV particles from barley protoplasts that were concentrated by sedimentation through a sucrose density cushion. We note that the recovery of the QC virions was less efficient when the same volume of the recovered materials was probed with antiserum to the BMV CP. The image to the right shows the same concentrations of RNAs recovered from a phenol-chloroform extraction and isopropanol precipitation were subjected to Northern blot analysis. The blot was probed to detect the $3^{\prime}$ UTR. The rRNA and Rubuisco subunits were not shown for the enriched virion preparations since they are not present. 
function of increased temperature (Yi et al. 2009b). The changes are measured by the binding of SYPRO Orange, which fluoresces upon binding exposed hydrophobic regions of proteins. The point of maximum increase in fluorescence will be called the apparent melting temperature $\left(\mathrm{Tm}_{\mathrm{app}}\right)$. Depending on the $\mathrm{pH}$ and the buffer, the Tm $\mathrm{m}_{\mathrm{app}}$ of the WT CP can approach $80^{\circ} \mathrm{C}(\mathrm{P}$. Ni, unpublished data). In an acetate buffer with a $\mathrm{pH}$ of 4.5 , the WT virion has two distinct melting transitions, a shallow one between 60 and $75^{\circ} \mathrm{C}$ and a sharper, likely cooperative, transition with a $\mathrm{Tm}_{\mathrm{app}}$ of approximately $79^{\circ} \mathrm{C}$ (Fig. 6A). The VC virion has a slightly altered melting profile but largely retains the same two transitions, with a sharp transition at $77^{\circ} \mathrm{C}$. In contrast, the QC mutant had multiple transitions between approximately 60 and $80^{\circ} \mathrm{C}$ (Fig. 6A).

DSF analysis was performed in the presence of the denaturant urea (Fig. 6B). The WT virion retained a sharp transition, although the $\mathrm{Tm}_{\mathrm{app}}$ changed from $78^{\circ} \mathrm{C}$ for the control lacking urea to 74 and $68^{\circ} \mathrm{C}$ in the presence of 1 and $2 \mathrm{M}$ urea, respectively. The QC virion exhibited broad and dramatic changes in the presence of increasing concentrations of urea, suggesting that the particles are both more heterogeneous and less stable than the WT. These results were consistent in three independently assayed samples.
BMV is normally more stable at acidic pH levels, at which virions are in a contracted conformation and have greater stiffness (Klug et al. 2006; Pfeiffer and Hirth 1974). At a higher $\mathrm{pH}$, the virion will undergo a dramatic structural transition (Pfeiffer and Hirth 1974). We used DSF to determine whether the stability of the QC virions was affected by $\mathrm{pH}$. All samples were assayed in phosphate buffers adjusted to $\mathrm{pH}$ levels from 5.5 to 8.1 ( $\mathrm{pH}$ levels were determined at room temperature). The QC virion was less stable than the WT at the acidic $\mathrm{pH}$ levels, with a $13^{\circ} \mathrm{C}$ difference in the $\mathrm{Tm}_{\text {app }}$ at $\mathrm{pH}$ 5.5. However, both virions exhibited the transition associated with a change from the contracted to the expanded conformations at approximately pH 6.5 (Fig. 6C). These results support the idea that, while the average stability of the QC mutant is less than WT, it retains one or more characteristic transitions as a function of $\mathrm{pH}$.

Dynamic light scattering (DLS) was used to further examine the hydrodynamic diameters of the WT and QC virions in response to changes in buffer $\mathrm{pH}$ and denaturants (Fig. 7). The majority of WT and QC virions exhibited a peak with a mean hydrodynamic diameter of 32 and $31 \mathrm{~nm}$, respectively, at a $\mathrm{pH}$ of 6.0. These measurements are within instrument accuracy for BMV particles (B. Dragnea, unpublished data). However, with
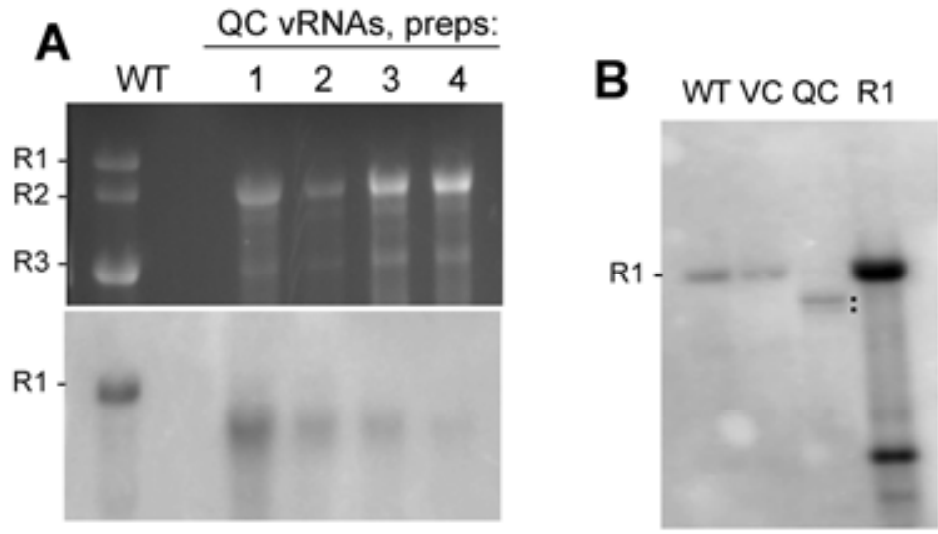

C B

D

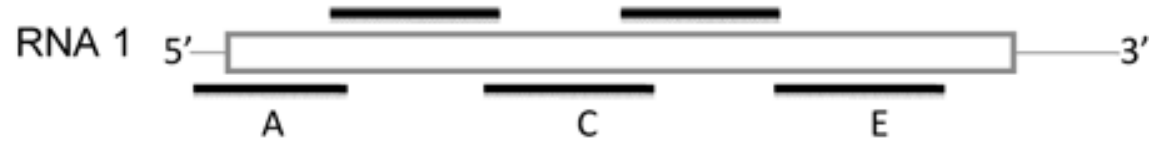

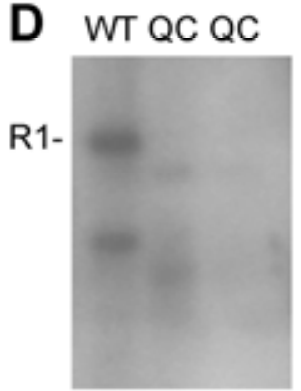

Probe: A

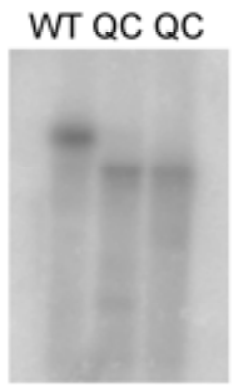

B

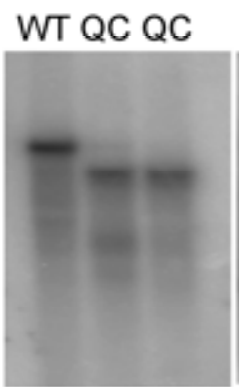

C



D

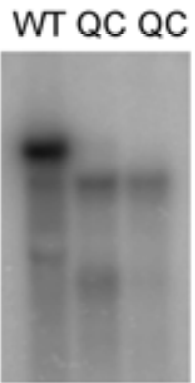

$\mathrm{E}$

Fig. 4. The Brome mosaic virus (BMV) RNAs in the QC (Q120C substitution mutant) virion. A, RNA1 is truncated in four independent QC virion preparations. The upper panel shows the ethidium bromide-stained total RNAs present in the wild-type (WT) and QC virion preparations. The lower panel shows the results of a Northern blot probed with an oligonucleotide specific to the open reading frame (ORF) encoded by BMV RNA1. The oligonucleotide was annealed to the positions of nucleotides 15 to 54 in the BMV 1a ORF. B, Additional evidence that BMV RNA1 is truncated. Virions from WT, VC, and QC prepared by $\mathrm{CsCl}$ density gradients were used to extract RNAs that were then probed with an oligonucleotide recognizing the $3^{\prime}$ portion of the 1 a ORF. There are at least two distinct bands recognized by the RNA1-specific probe in the QC preparation, and these are identified by periods to the right of the bands. The lane labeled R1 is from an in vitro transcript of BMV RNA1 and is used as a positive control. C, A schematic of a set of five random primer-labeled DNA probes (A through E) that spans the length of BMV RNA1. D, Results of probing the two different preparations of QC RNA with DNA probes shown in the schematic in panel $\mathrm{C}$. The names of probes used are shown as letters below the images of the blot results. 
the QC virion, we observed high polydispersity within the main peak and additional peaks in excess of $100 \mathrm{~nm}$ (Fig. 7). The larger diameter peaks also changed within the 10 to 20 runs used for the acquisition of each set of data, suggesting a dynamic organization (Fig. 7A). The WT preparation did not exhibit these at the low $\mathrm{pH}$ buffers, but a trace was also seen in buffers with $\mathrm{pH}$ levels of 7.2 to 7.6 (Fig. 7A). The major peak of the QC virions started to increase from $\mathrm{pH}$ levels 6.0 to 6.4 , while the hydrodynamic diameter of the WT virion was relatively unchanged. Interestingly, the QC virions reached a larger final diameter than that of the WT virion (Fig. 7B). These results are consistent with those for the DSF that demonstrated a defect in the $\mathrm{pH}$-dependent changes of the QC virion.

Materials of larger diameters were not abundant in either virion preparation in the absence of urea. In the presence of 1 or $2 \mathrm{M}$ urea, the QC virions exhibited new peaks with diameters of 70 and $130 \mathrm{~nm}$, respectively. A minimal amount of the approximately 30-nm peak was present under these conditions (Fig. 7C). However, the 32- to 36-nm peaks in the QC virion preparation were replaced with those having a larger hydrodynamic diameter at $3 \mathrm{M}$ urea, while the WT virion retained some of the 32-nm peak until the solution had $4 \mathrm{M}$ urea (Fig. 7D). These results confirm those from DSF that QC virions were more sensitive to denaturing conditions than the WT virions.
Electron microscopy of the QC virions.

Two data sets with over 30 micrographs of BMV WT and QC virions were stained with uranyl acetate, and the images were collected on a CCD camera to allow single particle reconstruction. The QC micrographs had smaller particles, some of them with irregular shapes (Fig. 8A). Measurement of the diameters of over 200 particles from over several randomly selected micrographs for the WT and QC virions revealed the distributions of sizes shown in Figure 8B. The WT virions had a normal distribution of particles, with an average diameter of $26 \mathrm{~nm}$, while the QC virions had a heterogeneous size distribution. We also observed a subclass of QC particles that appear to have lost a portion of the outer capsid (Fig. 8A, right panel) and have a plume associated with the breached area, suggesting that the particles were breached (Fig. 8C). The WT BMV particles did not exhibit this class of ruptured virions. Given that the QC virions used were purified over a cesium chloride density gradient, it is possible that these virus particles ruptured during the preparation of the samples for electron microscopy.

To better quantify the different classes of virus particles, we selected over 6,500 well-separated QC particles from 35 independent micrographs for sorting by the EMAN computer program without presumed symmetry. One subset with over 2,000
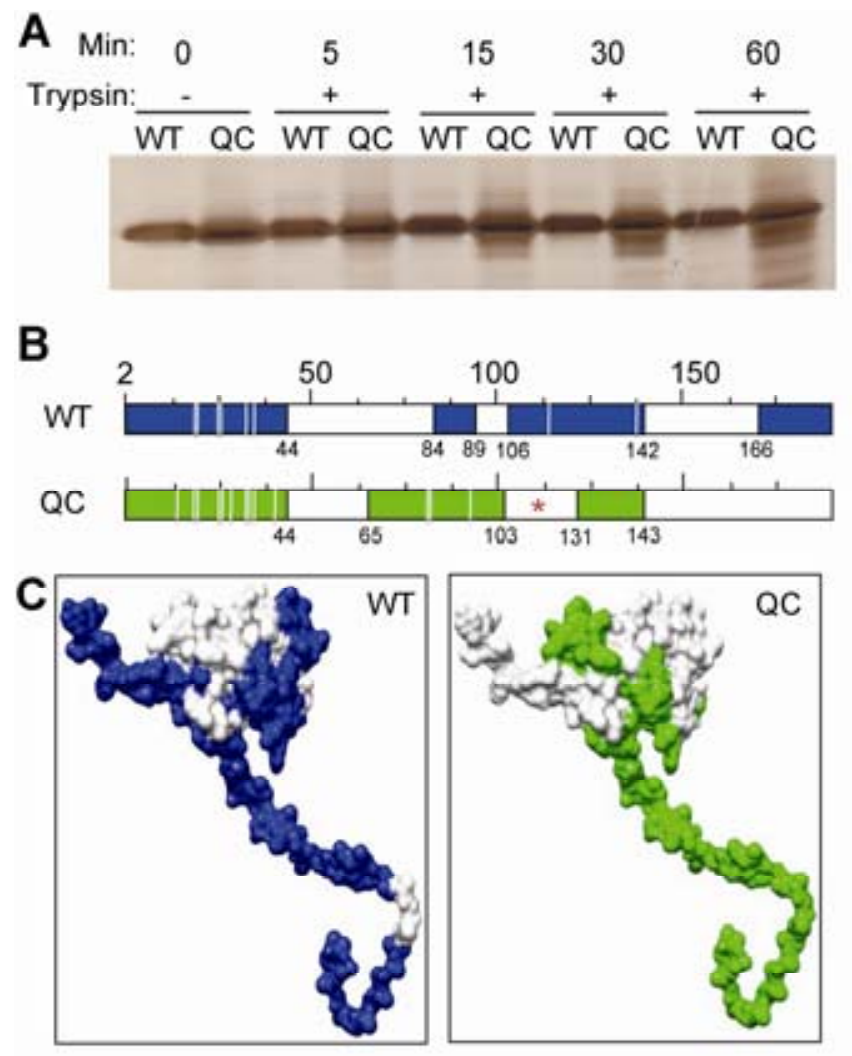
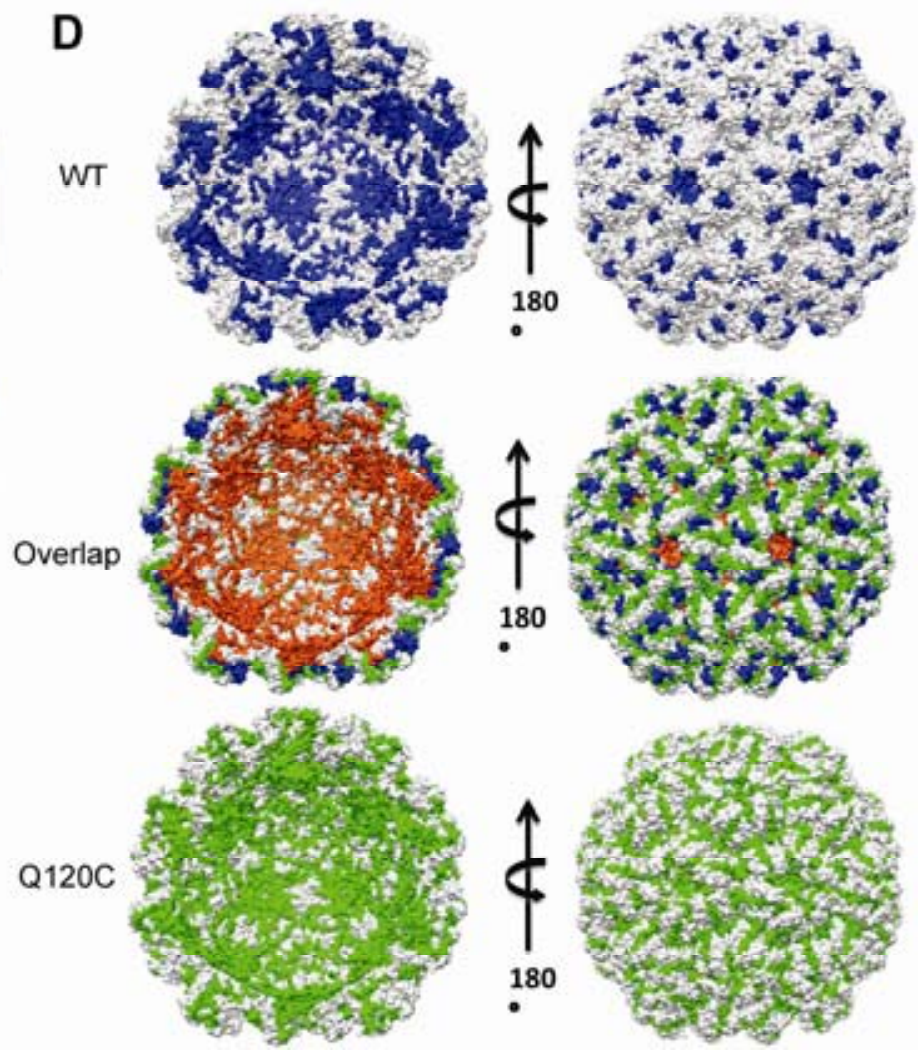

Fig. 5. Mapping of RNA-contacting regions in the wild-type (WT) and QC (Q120C substitution mutant) capsids. A, Partial trypsinization of the WT and QC virions to demonstrate differential susceptibility of the two virions to protease treatment over a course of time. The virions purified from CsCl gradients were treated in a master mix with a 50:1 molar ratio of capsid to trypsin. The reaction was performed in the VB, and aliquots were removed at the times indicated above the gel image and were stored on ice in the Laemmli sample buffer containing sodium dodecyl sulfate until all of the samples had been collected. The proteins were then electrophoresed on a 4 to $12 \%$ denaturing polyacrylamide gel and were stained with silver. B, A summary of the results of extensive trypsin treatment following purification of the RNAs from the WT and QC virions through reversible cross linking-peptide fingerprinting analysis (Yi et al. $2009 \mathrm{~b})$. The virions were treated with trypsin at a 1:1 (wt/wt) ratio overnight to allow complete digestion. Numerous peptides overlapped, and these regions are shown in blue for the WT and green in the QC capsid. The locations of the cleavages are shown as white lines within the colored regions. The location of Q120 is denoted with an asterisk. C, Locations of the peptide fragments that were crosslinked to virion-associated RNAs in monomers of the WT and QC capsids. Features in blue or green are the crosslinked peptides from the WT and QC capsids, respectively. D, The locations of the peptide fragments in the context of the Brome mosaic virus (BMV) virions. The two sets of views show the peptides that map within the central cavity of the virion and the exterior. All of the peptides were mapped into the crystal structure of the BMV (pdb 1JS9; Lucas et al. [2002]). Peptides from the WT virion are in blue and those from the QC virion are in green. Where the crosslinked regions overlap, they are shown in rust brown. 
particles had the 26-nm particles expected for normal BMV and retained the typical arrangements of capsomeres (Fig. 8D). The second set (group 2) also had over 2,000 particles and a diameter approximately $21 \mathrm{~nm}$, characteristic of a pseudo $T=2$ virion (Fig. 8E). Approximately 1,700 particles could not be fitted into the class averages for the above two models or with only one model. However, these could be roughly divided into 29 classes, each having between nine and 106 particles (Fig. 8F). These particles have diameters of approximately $21 \mathrm{~nm}$, similar to group 2. However, several classes had poorly defined borders and collapsed capsomeres (Fig. 8F). We propose that these are the virions that have lost RNAs or had fragmented RNAs.

\section{Additional mutants with altered RNA packaging.}

The analysis with the WC mutant raises the question as to whether mutations at other positions in the BMV capsid can result in altered RNA packaging, stabilities, or both of the particle. The residues at the interfaces of the BMV capsid subunits were selected for this analysis (Fig. 9A and B). Residue E131 is at the junction of the pore within a hexamer of the BMV capsomere, and its side chain coordinates $\mathrm{Mg}^{2+}$ ions (Lucas et al. 2002). E84 lies at the interface of an asymmetric trimer, and its side chain also coordinates $\mathrm{Mg}^{2+}$ ions (Lucas et al. 2002). Last, histidine 170 lies between neighboring capsomeres and could contribute to changes in virion structure in response to $\mathrm{pH}$. E131 and E84 were each substituted with five other residues (Ser, Gln, His, Tyr, and Ile) that will affect binding to divalent metal, while
His170 was substituted with a glutamate. Detailed characterization of these mutants for interaction with divalent metals and response to $\mathrm{pH}$ will be presented elsewhere, but all of the mutant proteins were able to produce virions.

Strikingly, several of the E131 substitutions exhibited altered viral RNA packaging. E131S, E131Q, and E131H had significantly decreased RNA1. E131S and E131H also had an obviously decreased abundance of RNA4. E131Y had a high abundance of RNA2 and very little RNA4 (Fig. 9C). The E84Q substitution and, to a lesser extent, E84H had reduced amounts of RNA4. Mutants E131I, E84S, E84Y, and E84I contain similar ratios of the RNAs as the WT (Fig. 9C). Lastly, the H170Q substitution was poor in encapsidating RNA3 and RNA4. We analyzed the replication of mutants E131Q, E131H, and E131Y and observed that at 2 days after agroinfiltration, the RNAs that were not properly represented in the virions were present in cells at approximately the expected ratios (Fig. 9D). These results rule out a replication defect for these mutants and demonstrate mutations that could affect the interaction between capsid subunits and have a selective effect on the RNA packaged.

\section{Virions with BMV RNA1}

exhibit differential sensitivity to $\mathrm{pH}$.

Mutations are often useful in defining the properties of molecules in their WT state. The lower abundances of RNA1 and possibly RNA3 and RNA4 in the BMV virions in com-

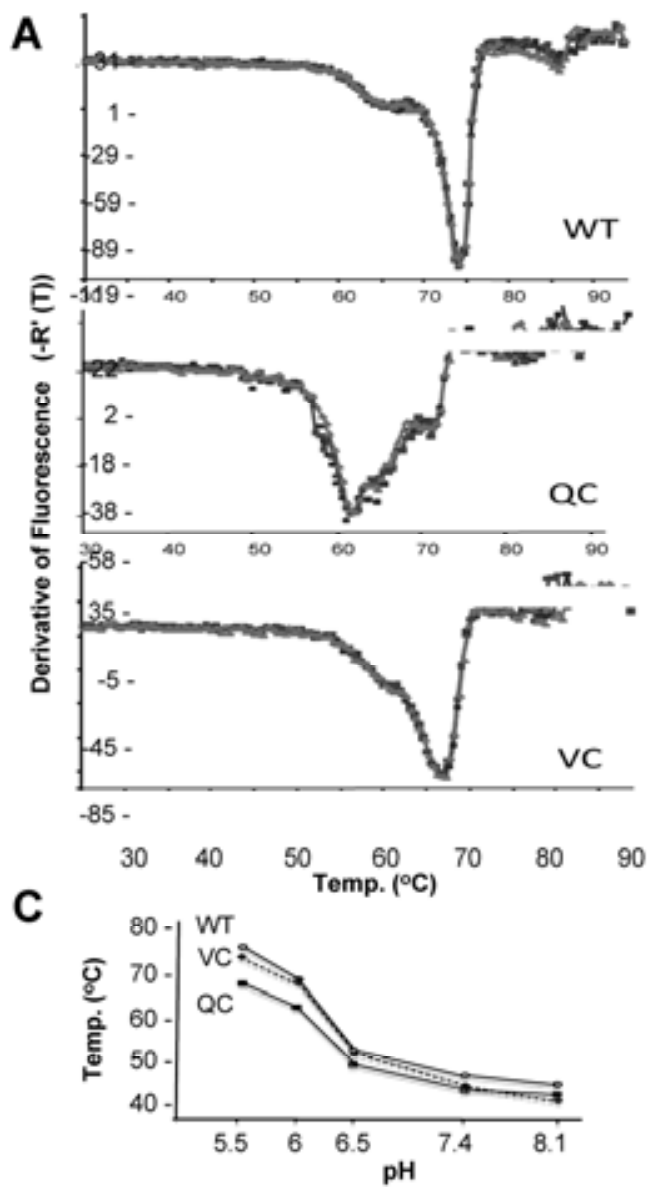

B

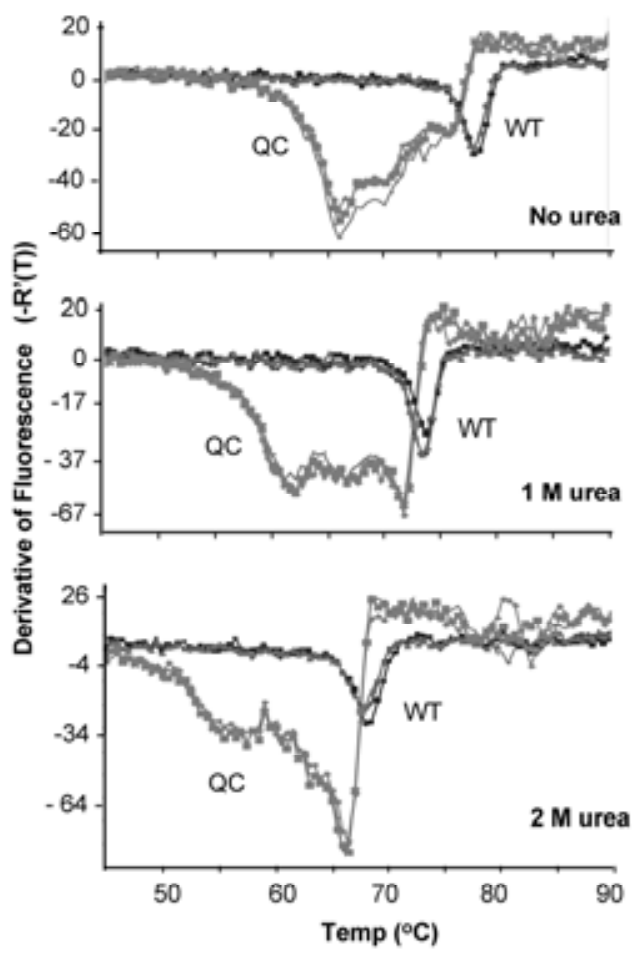

Fig. 6. Biochemical and biophysical characterizations of the QC (Q120C substitution mutant) virions. A, Differential scanning fluorimetry (DSF) to examine the stabilities of the wild-type (WT), QC, and VC (V168C substitution mutant)virions. The results shown are the first derivative of the fluorescence of SYPRO orange as a function of sample temperature. The point of maximum change in fluorescence is designated the apparent melting temperature. Each graph contains three independently assayed samples. B, Effects of urea on the denaturation profile of WT and QC virions. The virions were in a NaOAc buffer ( $\mathrm{pH}$ 5.5) and were subjected to the DSF assay. C, A summary of the changes in the most abundant peak in the WT and QC virions as a function of pH. The virions were equilibrated in phosphate buffers adjusted to the $\mathrm{pH}$ values shown in the graph and were then subjected to DSF. 
parison with that of RNA2 suggest that subsets of the WT BMV particles have differing stabilities. The QC substitution may exacerbate this difference, especially at higher $\mathrm{pH}$ levels at which BMV particles should swell. To examine this possibility, CsCl-purified WT BMV and QC virions were incubated in a phosphate buffer at $\mathrm{pH} 6.0$ or 7.0. The solutions were amended with micrococcal nuclease at $1 \mathrm{U}$ per $\mu \mathrm{g}$ of virus and $2.5 \mathrm{mM} \mathrm{CaCl}_{2}$ at $37^{\circ} \mathrm{C}$. Samples at time 0 were processed before the addition of the micrococcal nuclease and to facilitate quantification, Northern blot results probed to detect the $3^{\prime}$ UTR are shown (Fig. 10A). At pH 6.0, both the WT and QC virions retained the complement of the RNAs that were initially present over at least a 20 -min period. However, at $\mathrm{pH}$ 7.0, when BMV virions would have swelled, the WT RNA1 was more rapidly degraded relative to the WT RNA2 in the same solution. The QC virion was less stable over the same time course, and the RNAs were degraded in $10 \mathrm{~min}$ at $\mathrm{pH} 7.0$ Quantification of the amount of RNA1 and RNA2 are shown below the autoradiographs. These results show that even the subclasses of the particles in WT BMV virions have distinguishable properties in response to the solution $\mathrm{pH}$.

Differential stabilities of the virion particles containing distinct genomic RNAs should result in altered thermodynamic properties of the subsets of virions. Indeed, the WT BMV has two distinct transitions in the DSF assay as a function of increasing temperature (Fig. 6A). In these experiments, the subpopulation of the BMV virions cannot be distinguished. Therefore, we produced BMV virions that contained only RNA3 and RNA4 (named R34 virions) from $N$. benthamiana infiltrated to express the BMV 1a and 2a proteins along with RNA3. The

R34 virion was previously shown to produce good yields and was sufficiently homogeneous to grow two-dimensional crystals (Sun et al. 2007). Analysis of the RNAs from the CsCl-purified R34 particles revealed the expected RNAs and the capsid protein (Fig. 10B). In the DSF assay, the R34 virions exhibited a sharp transition, while the WT BMV virions exhibited an additional peak that denatured at a lower temperature (Fig. 10C). While this experiment cannot distinguish whether the lower temperature transition can be assigned to the particles containing RNA1, RNA2, or both, it clearly shows that the three BMV particles have distinct thermodynamic parameters.

\section{DISCUSSION}

How the viral capsid can recognize and interact with the RNAs is critical to successful infection. We identified a cysteine substitution at position 120, lying at the interface of BMV capsid subunits, that did not affect RNA replication but reduced the yield of the virions, and the RNAs that are associated with the recovered virions have unusual ratios. The $\mathrm{QC}$ virions exhibit modestly reduced BMV RNA2 but dramatically reduced RNA1 and RNA4 in both N. benthamiana (Fig. 2C) and barley protoplasts (Fig. 3B). Characterizations show that RNA1 was truncated. These results led us to hypothesize that the RNAs inside of the virions will affect the stabilities of the viral particles and that the QC mutation exacerbated the differential effects of the RNAs rather than differential packaging of the RNAs. Consistent with this, the particles containing RNA1 in WT BMV were more sensitive to nuclease digestion than those containing RNA2 (Fig. 10A). Furthermore, purified particles containing
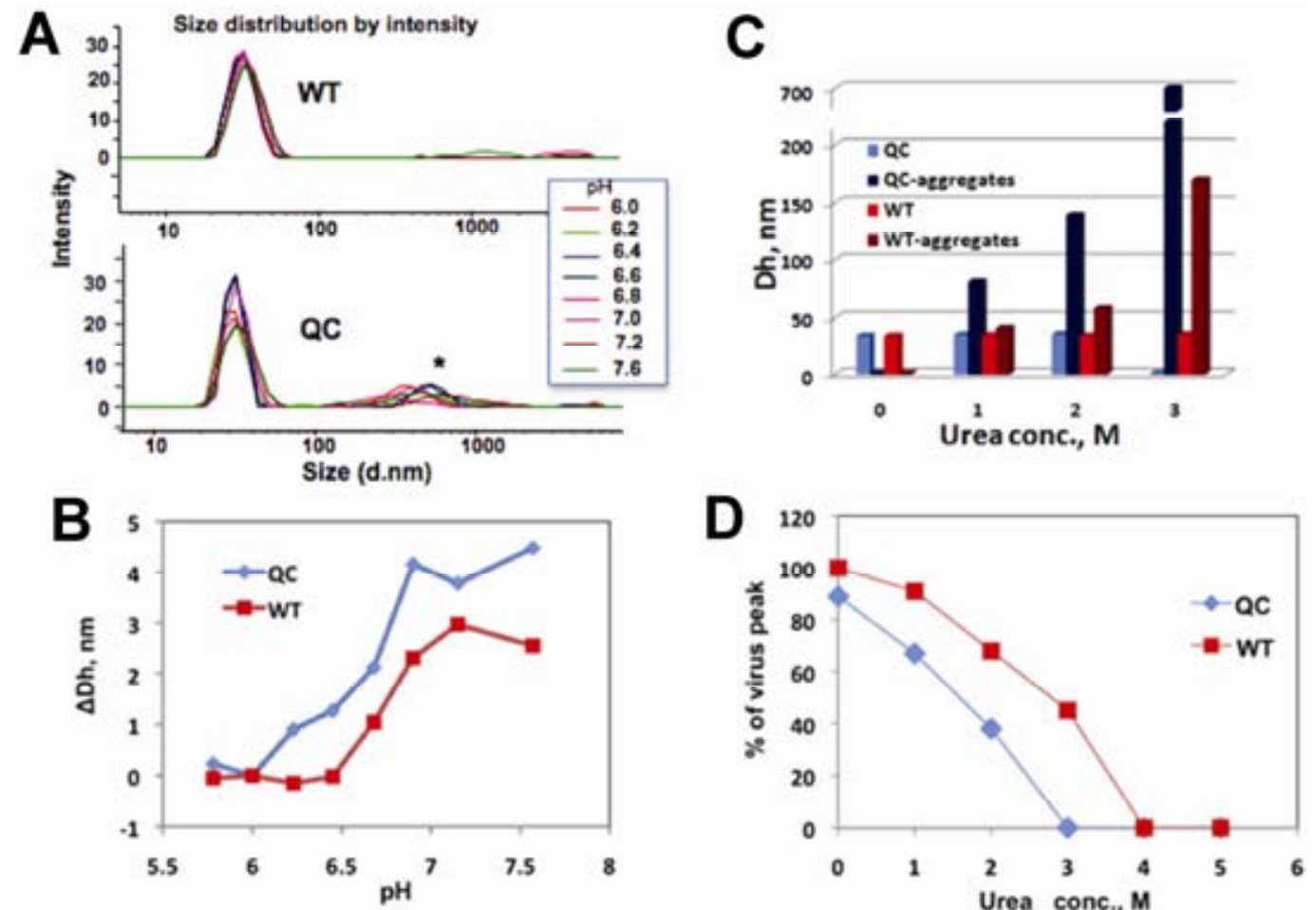

Fig. 7. Examination of the wild-type (WT) and QC (Q120C substitution mutant) virions using dynamic light scattering (DLS). A, A summary of all the raw data from DLS for the WT and QC virions examined, in phosphate buffer that ranged from pH 6.0 to 7.6. Each line shows the averaged data of a minimum of six runs. In some measurements, smaller peaks at 10 to $12 \mathrm{~nm}$ were observed in the QC sample, but the data analysis program removed these measurements because of high polydispersity in the sample. The asterisk identifies the heterogeneous material in excess of $100 \mathrm{~nm}$ that was not observed in the WT virions sampled from $\mathrm{pH} 6.0$ to 7.0. However, some were observed with measurements taken at $\mathrm{pH}$ 7.2 and 7.6. B, A summary of the changes in the hydrodynamic diameter of the WT and QC virions as a function of pH. Only the change in the diameters of the approximately 31- to 36-nm peaks was plotted. C, Size of the new peaks (labeled aggregates) appearing in QC and WT virions as a function of the denaturant, urea. Virus stock solution (5 $\mu$ l of a 1-mg/ml concentration) was mixed with $45 \mu$ l of urea solution with appropriate concentrations. DLS measurements were acquired after 24 h. D, A summary of the amount of the WT or QC virions present as intact virions as a function of urea concentration. The samples that are approximately 31 to 36 nm are designated as intact virions. Other signals are designated as aggregates. 
RNA3 and RNA4 had different stabilities for the encapsidated RNA when compared with the WT BMV particles (Fig. 10C).

We speculate that RNA2 is less affected in the QC virions because it can interact more stably with the capsid due to its length or, as a function of length, its mass to charge ratio within the virion. The virion containing RNA2 has the fewest number of nucleotides, 2,865 nt. The RNA1 virion is longer than RNA2 by 369 nt. The copackaged RNA3 and RNA4 are longer than RNA2 by 118 nt. Perhaps the smaller mass or charge, or both, within the RNA2 virions exert less pressure from within the virion when the capsids contract in acidic buffers. The QC change, being at the interface of capsid subunits, could weaken the capsid shell under some conditions encountered by the virion, such as a change in $\mathrm{pH}$. If the capsid cannot interact as stably with the RNA, some of the RNAs could be more easily exposed and susceptible to ribonucleases present in the plant.

Two observations are consistent with this model for the effects of RNA inside the QC virions. First, the small amount of RNA1 that is retained in the QC virions is truncated to a length comparable to that of RNA2 (Fig. 4C). Second, virionassociated RNAs from barley protoplasts did not alter the abundance of RNA3 when compared with RNAs from WT virions. BMV virion expansion and contraction is a reversible process. If RNA1 is, by chance, cleaved near a terminus and the shorter fragment is dissociated from the virion, the remaining RNA could be better protected when the QC virions now have to deal with a shorter (or less charged) RNA. Also, if RNA3 were packaged separately from RNA4, as appears to be the case with the QC mutant virions produced in barley, the mass to charge ratio in the RNA3 particles could alter the virion structure and affect stability.

Proper protection of the RNA by the capsid is likely imparted by a virion's response to microenvironments encountered during infection. Fully expanded leaves are used for agroinfiltration, but BMV spreads to the plant's vasculature, into the phloem, and usually, toward the developing leaves near the meristem (Gopinath and Kao 2007). It is likely that different parts of the plant will present distinct conditions for the virions. Consistent

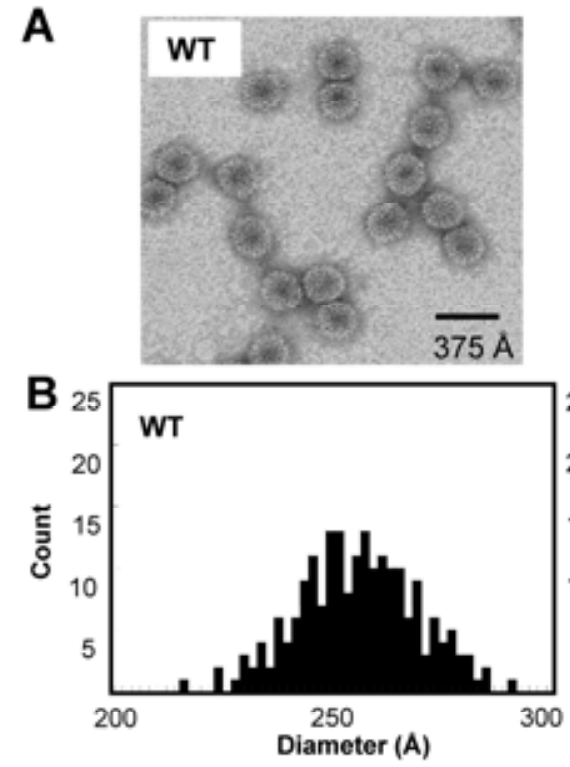

D

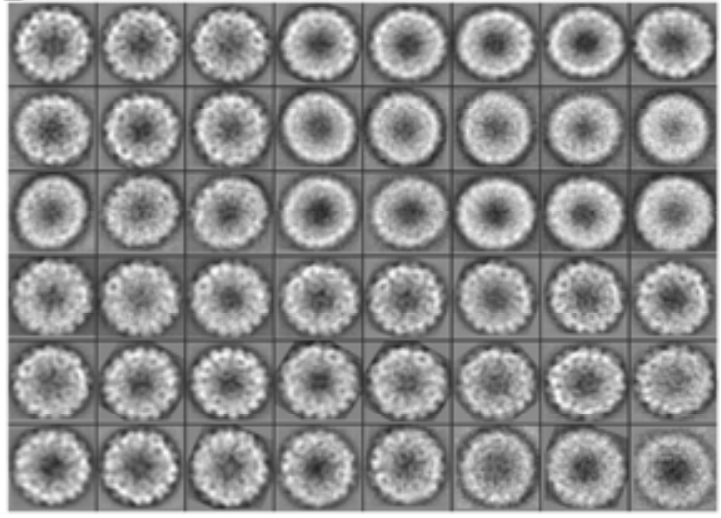

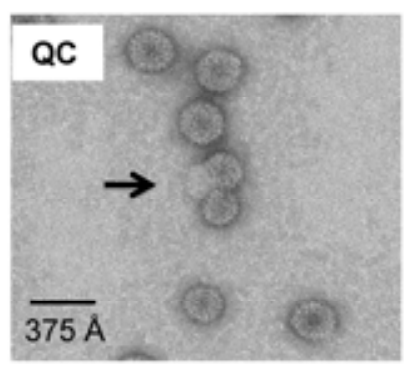

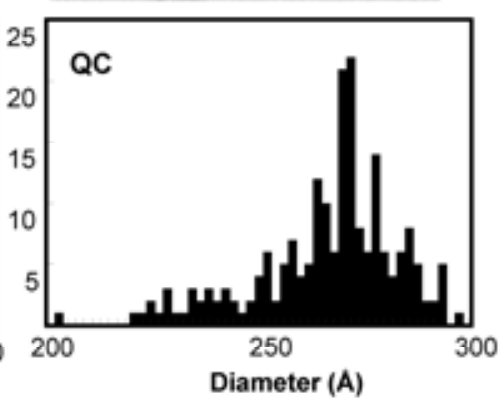

$\mathrm{E}$

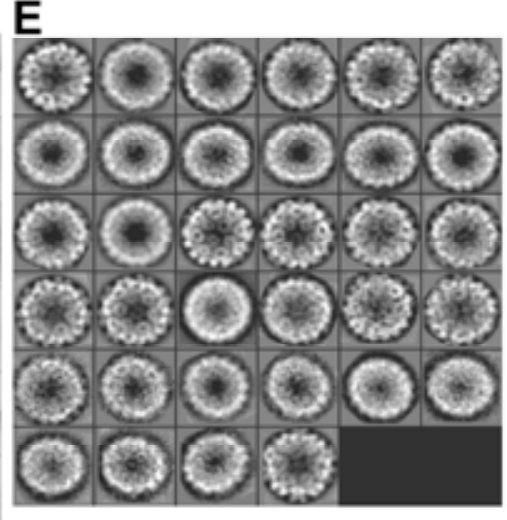

C

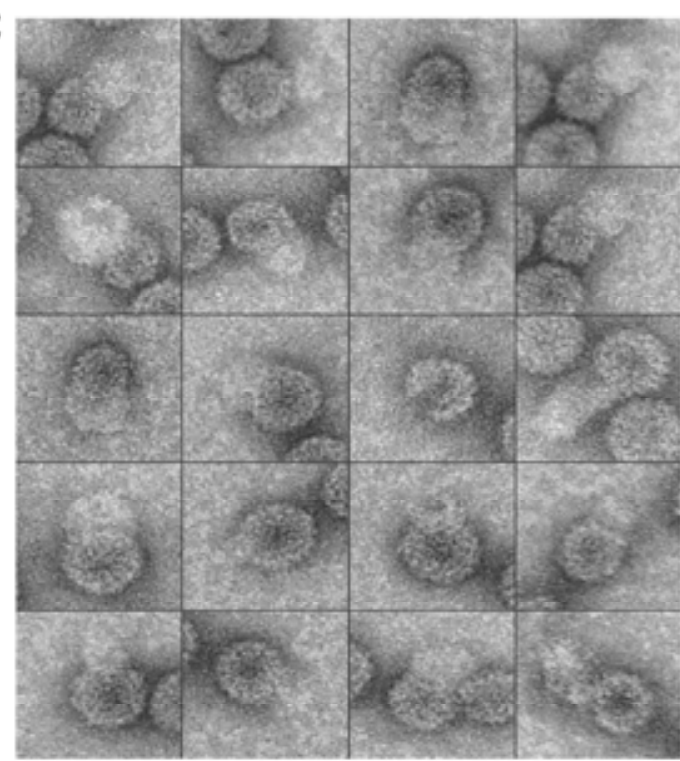

$\mathbf{F}$

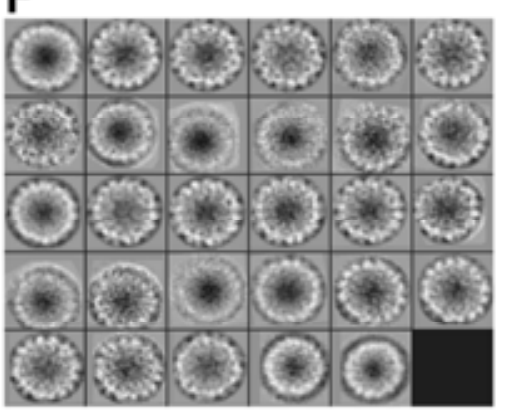

Fig. 8. Analysis of wild-type (WT) and QC (Q120C substitution mutant) virions by electron microscopy. A, Sample images of WT and QC virions that have been purified over $\mathrm{CsCl}$ density gradients. The samples were adjusted concentrated to $100 \mathrm{ng} / \mu \mathrm{l}$ and were stained with $1 \%$ uranyl acetate. Images were taken at 40,000× magnification with a JEOL 1010 microscope. The arrow shows a QC virion that has lost one side of the particle and also contains what may be leaked RNA. B, Distributions of the diameters of the viral particles in WT and QC virions. The outer diameters of all of the particles were measured from four sample micrographs to generate the data plotted in the bar graph. The results show a greater degree of heterogeneity in the QC particles. C, A gallery of the herniated QC virions. These particles are present at approximately 1\% of the QC virions and are absent in micrographs of WT and VC (V168C substitution mutant) virions (data not shown). D through F, Class averages of three subclasses of QC virions identified by the multirefine feature of the EMAN programs. D, Class averages of the approximately 26-nm QC virions. Over 2,000 particles from a total of 6,500 selected from 33 micrographs were sorted into this class of particles. E, Class averages from the approximately 20-nm particles. Over 2,000 particles from the 6,500 were sorted into this class. F, The remainder of the particles. We note that some have apparently lost one edge of the virion, suggesting that the structural integrity of the particles was affected. 
with potential host-derived differences, we observed different RNA ratios present in the QC virions produced in $N$. benthamiana versus those produced in barley protoplasts (Fig. 3B). In addition, while the $\mathrm{QC}$ virion can be recovered and purified, it cannot systemically infect the plant. When disassembled, the QC capsids cannot be reassembled into virus-like particles, even in the presence of RNA (data not shown).

We emphasize that the destabilization of the RNAs does not imply that the RNAs are intrinsically more or less stable. In fact, a structural defect in the capsid that is likely influenced by environmental conditions must precede the degradation of the RNA. Furthermore, the QC mutant is not unique and differential packaging or stability, or both, of the encapsidated RNAs are observed with single amino-acid substitutions at the interfaces of capsid subunits (Fig. 9). Calhoun and associates (2007) also observed a similar effect on the encapsidated RNAs, although they reported that the RNAs are differentially packaged. We note with interest that different substitutions at residue E131 altered the abundances of the encapsidated RNAs in different ways (Fig. 9B). These results suggest that there is a greater plasticity in the packaging of the four BMV RNAs than was previously appreciated. In this vein, Michel and colleagues (2006) found that a single amino-acid change (K42R) in the Cowpea chlorotic mottle virus capsid could increase the stiffness of the viral particles.

The differential loss of the RNAs in the QC virions also suggests that the BMV RNA is not a passive cargo. Instead, the RNAs could shape the virus architecture and affect stability of the virion and the release of the RNAs. Based on our characterizations, the BMV particle containing RNA1 would be the least stable and more prone to spontaneous disassembly, while those containing RNA2 would be the most stable. This ordered disassembly would express the 1a methyltransferase-helicase first. The 1a protein is involved in the formation of the membrane-associated environment needed for BMV replication and has been shown to interact with the $2 \mathrm{a}$ protein and with BMV RNAs to recruit the 2a polymerase to the replication complex (Chen et al. 2001). An ordered disassembly of the viral RNAs could be advantageous to the timing of viral RNA gene expression.

In summary, our characterization of the Q120C substitution identified a position in the BMV virion that affected proper changes in the conformation of the virion that affects the encapsidated RNA. Other amino-acid substitutions also
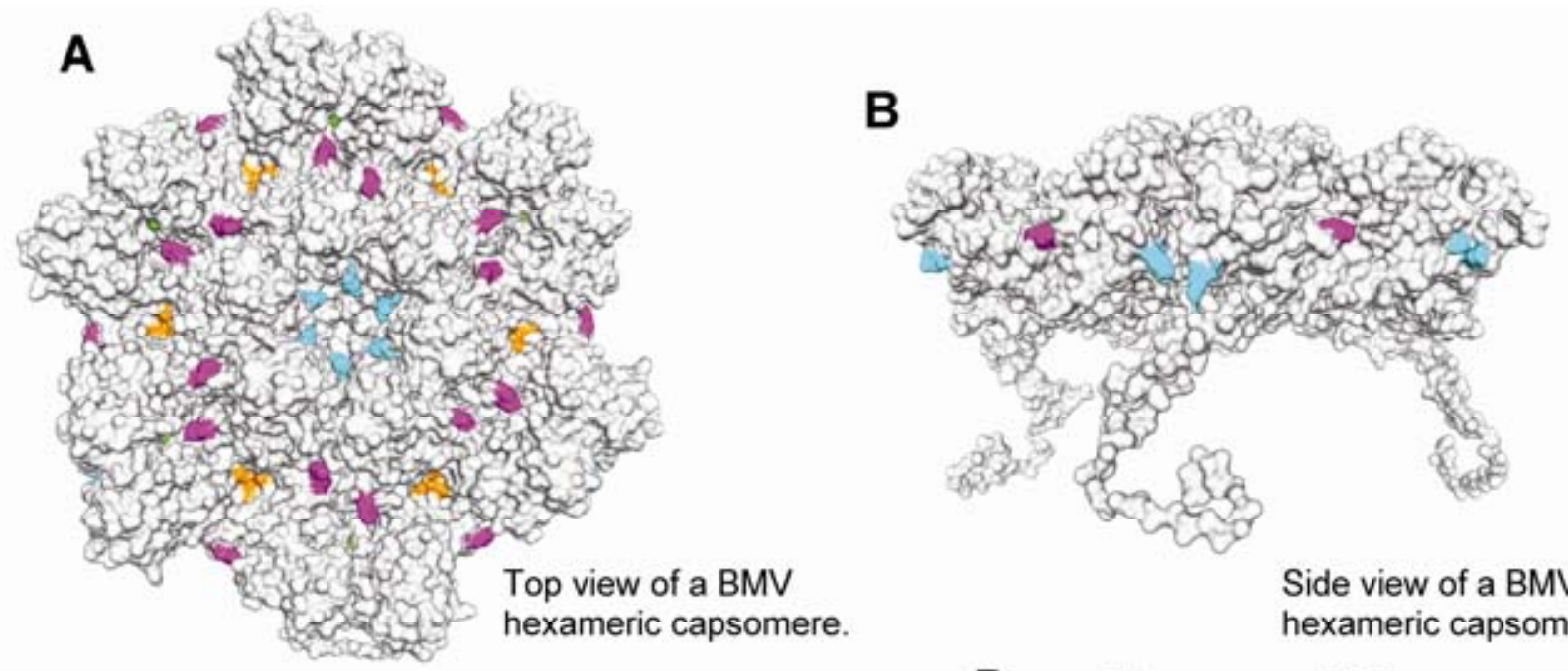

Top view of a BMV

Side view of a BMV hexameric capsomere
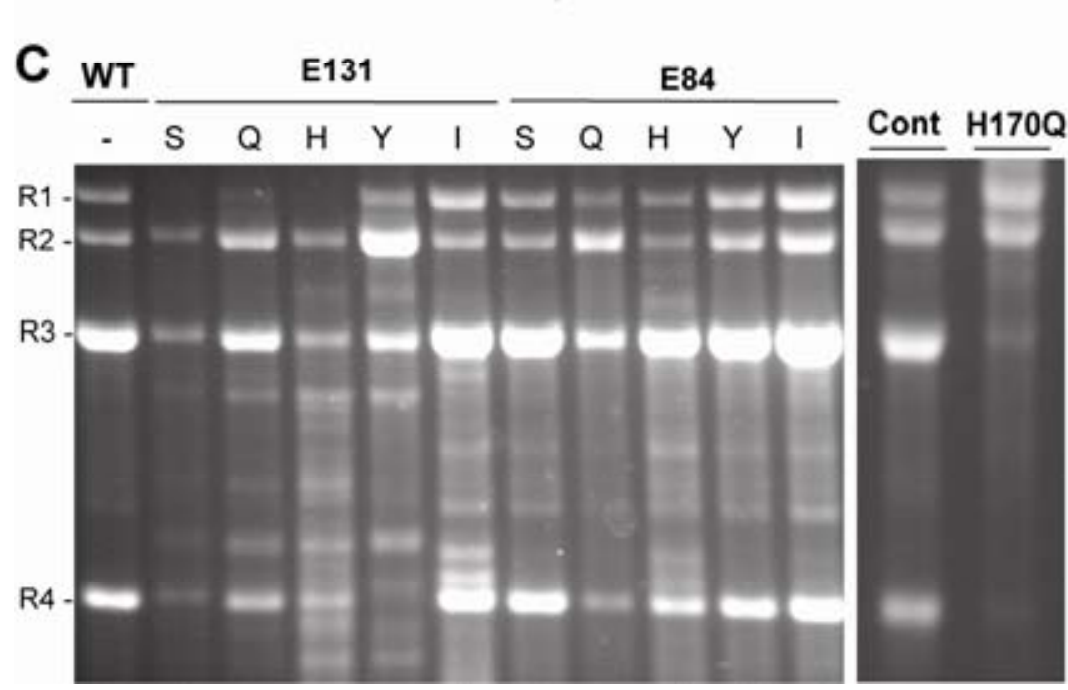

D

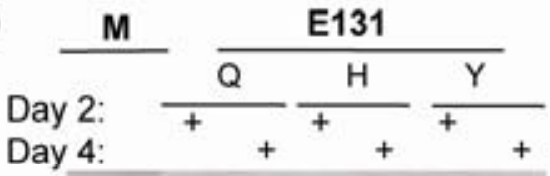

Fig. 9. Additional capsid mutations can affect the RNAs packaged. A, Top and side views of Brome mosaic virus (BMV) capsid hexamer. The locations of E131 (sky blue), E84 (light orange), and H170 (magenta) are shown. B, Effects of amino-acid substitutions at E131, E84, and H170 on the packaging of virion RNAs. All of the virions were purified from agroinfiltrated Nicotiana benthamiana and were purified by a sucrose density gradient. The RNAs were then purified from the virions by phenol-chloroform extraction and were electrophoresed in a $1.2 \%$ agarose gel. The substituted amino acids are denoted with the standard single letter code. The sample labeled "Cont" contains a preparation from an unrelated mutant virion that was unaffected in the ratios of the packaged vRNAs. C, Northern blot analysis demonstrating that three substitutions at E131 that affected RNA packaging were not significantly affected for viral RNA accumulation. Each sample $(5 \mu \mathrm{g})$ was loaded in the gel, and the blot was probed to detect the conserved 3' untranslated region of the BMV RNAs. 
had selective effects on either the encapsidation, degradation, or both of the BMV genomic RNAs. These results with the mutant virions allowed us to determine that the three classes of the WT BMV virions also have distinct stabilities that influence in the initial stages of infection when the RNAs leave the capsid.

\section{MATERIALS AND METHODS}

\section{Constructs for Agrobacterium-mediated BMV production in $N$. benthamiana.}

The Agrobacterium-mediated gene delivery system used to express the three BMV genomic RNAs was developed (Gopinath et al. 2005). cDNA for BMV RNA3 expressing the mutant CP was made by PCR-mediated site-directed mutagenesis with appropriate primers. The sequences of the cDNAs were confirmed to have no other mutations. All oligonucleotides were synthesized by IDT Inc. (Coralville, IA, U.S.A.).
Recombinant T-DNAs delivered by Agrobacterium tumefaciens infiltrated into Nicotiana benthamiana were used to express BMV genomic RNAs (Gopinath et al. 2005). Agrobacterium tumefaciens $\mathrm{C} 58 \mathrm{C} 1$ harboring one or more of the desired plasmids was infiltrated as described (Yi and Kao 2008). The plants were grown in an environmentally regulated growth chamber set to a relative humidity of $70 \%$, a constant temperature of $25^{\circ} \mathrm{C}$, and a 16 -h light and 8 -h dark regime.

\section{BMV purification.}

At 7 days postinfiltration, $N$. benthamiana leaves were homogenized in a $1: 3$ ratio of virus buffer ( $\mathrm{VB}, 50 \mathrm{mM} \mathrm{NaOAc}$ and $10 \mathrm{mM} \mathrm{MgCl}_{2}$ [pH 4.5]), and the supernatant was clarified by extraction with $10 \%$ chloroform for $10 \mathrm{~min}$, followed by centrifugation at $17,000 \times g$ for $10 \mathrm{~min}$ as described (Rao and Grantham 1995). The supernatant was layered on a $10 \%$ sucrose cushion prepared in VB and was centrifuged for $3 \mathrm{~h}$ at $96,000 \times g$ to pellet the virions. The pellets were dissolved in a
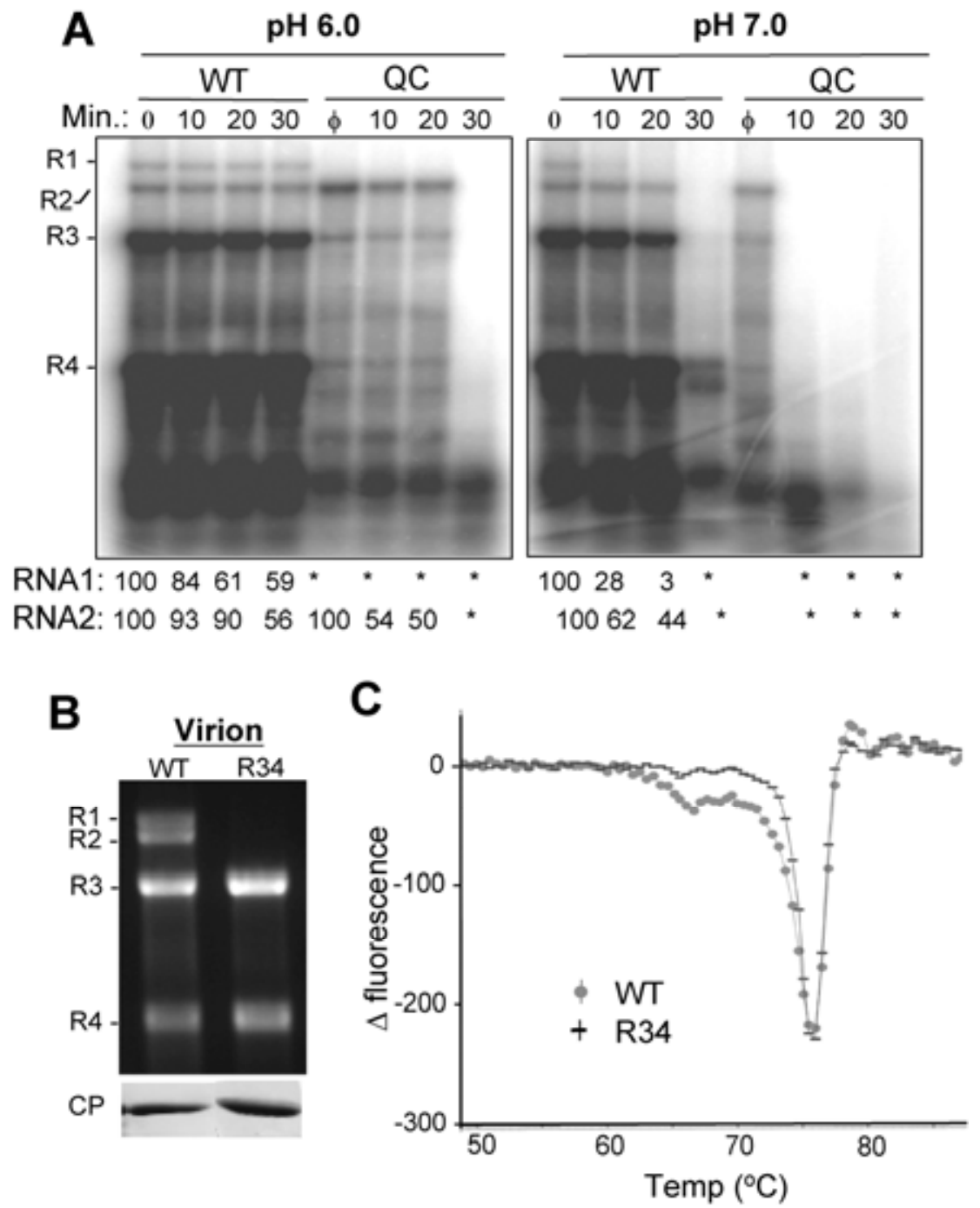

Fig. 10. Wild-type Brome mosaic virus (BMV) contains subsets of particles with distinct properties. A, Differential susceptibility of RNAs in BMV virions to micrococcal nuclease as a function of $\mathrm{pH}$. A master solution was equilibrated in $\mathrm{pH} 6$ or $\mathrm{pH} 7$ phosphate buffer containing 2.5 mM $\mathrm{CaCl}_{2}$ and micrococcal nuclease ( 1 gel unit per $\mu \mathrm{l}$ ). Samples were taken from the master mixes at the times indicated about the gel images and were stopped by the addition of EGTA to $5 \mathrm{mM}$. The RNAs were then subjected to phenol-chloroform extraction and Northern blot analysis. The experiments were all performed at the same time along with samples subjected to reactions at $\mathrm{pH}$ 6.5, which showed intermediate sensitivity of BMV RNA1 to micrococcal nuclease treatment (data not shown). B, Comparison of the RNAs and capsids of WT BMV virions and BMV virions containing only RNA3 and RNA4 (R34). The RNAs were electrophoresed in a denaturing 1\% agarose gel that was stained with ethidium bromide. The capsids in the two preparations (bottom panel) were electrophoresed in sodium dodecyl sulfate-polyacrylamide gel and were stained with silver (bottom panels). C, R34 virions (BMV virions containing only RNA3 and RNA4) have different stabilities in comparison with the wild-type BMV virions when analyzed by differential scanning fluorimetry, which measures the denaturation of the sample. 
$37.5 \% \mathrm{CsCl}$ solution and were banded by centrifugation at $209,000 \times g$ in a Beckman MLA 80 rotor for $20 \mathrm{~h}$. The band of virions was collected with a 3-ml syringe fitted with a 23gauge needle, was dialyzed with a minimum of three changes of SAMA buffer (50 mM NaOAc, 8 mM MgOAc, pH 5.4), and was stored at $-80^{\circ} \mathrm{C}$ until use.

Dissociated CP for mass spectrometry were prepared from $\mathrm{CsCl}$-purified virions by dialysis in $500 \mathrm{mM} \mathrm{CaCl}$, $(\mathrm{pH} 7.4)$ for $24 \mathrm{~h}$ at $4{ }^{\circ} \mathrm{C}$. Following centrifugation at $48,900 \times g$ for 40 min to remove the precipitated RNAs, the supernatant containing $\mathrm{CP}$ was dialyzed in buffer containing $10 \mathrm{mM}$ Tris$\mathrm{HCl}(\mathrm{pH} \mathrm{7.5)}$ for $24 \mathrm{~h}$, followed by dialysis in TKM buffer (10 mM Tris, $5 \mathrm{mM} \mathrm{MgCl}, 1 \mathrm{M} \mathrm{KCl}$ ) for $24 \mathrm{~h}$. The concentration of dissociated $\mathrm{CP}$ was determined by spectrophotometry and was checked for purity by SDS-PAGE (Laemmli 1970). A Waters/Micromass LCT Classic, which is an electrospray ionization-TOF mass spectrometer, coupled with a Waters CapLC with a C8 column was used for the analysis, using solvents A $\left(95 \% \mathrm{H}_{2} 0,5 \%\right.$ acetonitrile, $0.1 \%$ formic acid) and $\mathrm{B}$ (95\% acetonitrile, $5 \% \mathrm{H}_{2} 0,0.1 \%$ formic acid). Samples were introduced with solvent $\mathrm{A}$ to allow binding to the column. Solvent B was then used to elute the CP (all three samples showed the same elution profiles). Capillary voltage was 3 to $4 \mathrm{~V}$, extraction voltage was $3 \mathrm{~V}$, and the sample cone voltage for ionization was $40 \mathrm{~V}$.

\section{RCAP analysis.}

QC and WT virions $(2 \mu \mathrm{M})$ were treated or mock treated with formaldehyde at a final concentration of $0.1 \%$ in a $25-\mu 1$ reaction at room temperature for $5 \mathrm{~min}$. The reaction was terminated by the addition of glycine to a final concentration of $0.2 \mathrm{M}$. After $5 \mathrm{~min}$, sequencing grade trypsin (Trypsin Gold; Promega, Madison, WI, U.S.A.) was added at a protease/substrate ratio of

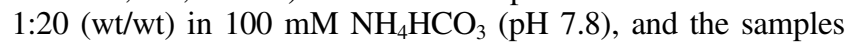
were incubated overnight at $37^{\circ} \mathrm{C}$. Unbound peptides were washed with $20 \mathrm{mM}$ HEPES (pH 7.5), $1 \mathrm{M} \mathrm{NaCl}, 1 \mathrm{mM}$ EDTA, and $1 \mathrm{mM}$ dithiothreitol. The mixture was then precipitated with $1 \mathrm{M} \mathrm{LiCl}$ to selectively precipitate the RNA. The precipitation was repeated twice to remove noncovalently linked peptides. Nucleotide-peptide conjugates were then reversed by incubating the samples at $70^{\circ} \mathrm{C}$ for $1 \mathrm{~h}$. The samples were centrifuged at $3,000 \times g$ for $5 \mathrm{~min}$, and the supernatants containing the peptides were desalted using a Ziptip (Millipore, Bedford, MA, U.S.A.). The bound peptides were eluted in $2.5 \mu \mathrm{l}$ of $70 \%$ acetonitrile and $0.1 \%$ trifluoroacetic acid and were analyzed by MALDI-TOF mass spectrometry.

\section{BMV infection in barley protoplasts.}

Isolation of barley protoplasts (Hordeum vulgare cv. Statehood) was performed as described previously (Kroner et al. 1990). Wild-type or mutant transcripts were made using in vitro AmpliCap-Max T7 high-yield message maker kit (Epicentre Biotechnologies). BMV RNA1, RNA2, and RNA3 transcripts $(2 \mu \mathrm{g}$, each) in $10 \mu \mathrm{l}$ of distilled water and $400 \mu \mathrm{l}$ of a solution of $40 \%$ PEG4000 [wt/vol], $0.2 \mathrm{M}$ mannitol, and 100 $\mathrm{mM} \mathrm{CaCl} 2$ were mixed with approximately 0.5 to $1.0 \times 10^{6}$ protoplasts in $100 \mu \mathrm{l}$ of $10 \%$ mannitol solution with gentle swirling. Protoplasts were washed twice with $10 \%$ mannitol and were incubated in $0.5 \mathrm{ml}$ of incubation medium $(0.2 \mathrm{mM}$ $\mathrm{KH}_{2} \mathrm{PO}_{4}, 1 \mathrm{mM} \mathrm{KNO}, 1 \mathrm{mM} \mathrm{MgSO}, 10 \mathrm{mM} \mathrm{CaCl}_{2}, 1 \mu \mathrm{M}$ $\mathrm{KI}, 0.01 \mu \mathrm{M} \mathrm{CuSO}_{4}$ and $0.5 \mathrm{M}$ mannitol [pH 6.5]) at $25^{\circ} \mathrm{C}$. To enrich for virions, protoplasts were suspended in VB and were disrupted by an Ultrasonic homogenizer. Cell debris was removed by centrifugation at $18,000 \times g$ for $20 \mathrm{~min}$. The supernatant was loaded onto a sucrose cushion (10\% sucrose, 50 $\mathrm{mM} \mathrm{NaOAc}$ [pH 4.5], and $10 \mathrm{mM} \mathrm{MgOAc}$ ) and was centrifuged at $135,000 \times g$ for $3 \mathrm{~h}$. The precipitates were suspended in VB and were immediately extracted for virion RNAs by adding a 1:1 ratio of phenol/chloroform and vortexing for 1 min. The aqueous layer containing the RNAs was precipitated with isopropanol. Total proteins were analyzed by SDS-PAGE, and coat protein was detected by Western analysis, using $\mathrm{CP}$ specific antibody from the ATCC.

Northern blots were performed with $5 \mu \mathrm{g}$ of total RNA per sample. The RNAs were treated with glyoxal reaction mix as described in Hema and Kao (2004) for $1 \mathrm{~h}$ at $55^{\circ} \mathrm{C}$, after which they were electrophoresed in a $1.2 \%$ agarose gel. After transferring the RNA to nylon membrane, the membranes were probed with $\alpha^{32} \mathrm{P}$-labeled strand-specific riboprobes (Hema and Kao 2004). All signals in the Northern blots were quantified using ImageQuant software.

\section{Analysis of RNA replication in $N$. benthamiana.}

Total RNA was extracted from $50 \mathrm{mg}$ of leaf tissue by macerating with disposable pestles in a lysis buffer $(0.1 \mathrm{M}$ glycine, pH 9.0; $40 \mathrm{mM}$ EDTA, $100 \mathrm{mM} \mathrm{NaCl}, 2 \%$ SDS, and $0.05 \%$ bentonite) (Choi et al. 2000; Kroner et al. 1990). The lysate was extracted with an equal volume of a 1:1 phenol and chloroform solution, followed by precipitating the RNAs with an equal volume of isopropanol. RNA concentration was determined using a nanodrop spectrometer, followed by analysis of $5 \mu \mathrm{g}$ of RNA by agarose gel electrophoresis and staining with ethidium bromide. Northern blots were performed by using either an in-vitro transcribed $3^{\prime}$ UTR riboprobe, a 5' terminally labeled oligonucleotide, or random primer-labeled DNA probes (Sambrook and Russell 2001).

\section{RT-PCR.}

RNAs used for RT-PCR were purified using the MiniRNA Easy kit following the manufacturer's protocol (Qiagen Corp., Valencia, CA, U.S.A.) and were then treated with RNase-free DNase I at $37^{\circ} \mathrm{C}$ for $20 \mathrm{~min}$. The DNase I was then inactivated by heating the sample at $95^{\circ} \mathrm{C}$ for $5 \mathrm{~min}$. WT and QC RNAs (100 and $1 \mathrm{ng}$, respectively) was used for the reaction. Reverse transcription used SuperScript II reverse transcriptase following the protocol described by the manufacturer (Invitrogen Inc., Carlsbad, CA, U.S.A.). Quantitative PCR was performed with the pairs of primers shown in Supplementary Table 1 (B1RTF1SP+ B1RTF1ASP, etc.), using iScript one-step RT-PCR SYBR green kit (Bio-Rad, Hercules, CA, U.S.A.) in a Realplex Mastercycler machine (Eppendorf, Hamburg, Germany).

A typical PCR protocol used 35 cycles of denaturation at $95^{\circ} \mathrm{C}$ for $30 \mathrm{~s}$, annealing at $55^{\circ} \mathrm{C}$ for $30 \mathrm{~s}$, and extension at $72^{\circ} \mathrm{C}$ for $1 \mathrm{~min}$. PCR products were examined in agarose gels and were stained with ethidium bromide. If the PCR products were used for sequencing, they were cloned into pGEM-T Easy vector (Promega, Inc., Madison, WI, U.S.A.). DNA sequencing used the Big Dye kit (Roche, Mannheim, Germany).

\section{DSF.}

DSF was performed in a 96-well plate in a Stratagene (La Jolla, CA, U.S.A.) real time PCR machine. Each sample had a total volume of $20 \mu \mathrm{l}$ containing $4 \mu \mathrm{g}(0.2 \mathrm{mg} / \mathrm{ml})$ of virion and SYPRO orange (Molecular Probes, Eugene, OR, U.S.A.) at $2.5 \times$ final concentration in VB, unless stated otherwise. Each sample was tested in triplicate. The 96-well plate containing all of the samples was heated from 25 to $95^{\circ} \mathrm{C}$ at a rate of $1.0^{\circ} \mathrm{C}$ per min, and the fluorescence intensity was measured with Ex/Em wavelengths of 470:550 $\mathrm{nm}$. Tmapp values were calculated using Kaleidagraph (Synergy Software, Reading, PA, U.S.A.). If urea was added to the sample, it was to a final concentration of 1 or $2 \mathrm{M}$. 


\section{DLS.}

DLS measurements were carried out with a Zetasizer NanoS (Malvern Instruments, Worcestershire, U.K.). The samples were prepared by mixing $5 \mu \mathrm{l}$ of virus stock solution (concentration of $1 \mathrm{mg} / \mathrm{ml}$ ) and $45 \mu \mathrm{l}$ of phosphate buffer adjusted to the appropriate $\mathrm{pH}$. Measurements were done $15 \mathrm{~min}$ after dilution to allow equilibration of the samples. Measurement duration was according to the preset levels, and the intensity and volume distributions of the particles from at least six runs were recorded in each data set.

\section{Electron microscopy.}

BMV virus particles in $10-\mu \mathrm{l}$ samples were adsorbed to a freshly glow-discharged carbon-coated copper grid and were negatively stained with $1 \%$ uranyl acetate for $20 \mathrm{~s}$ and visualized at an effective magnification of approximately $60,000 \times$ with a JEOL JEM 1010 electron microscope at an operating voltage of $80 \mathrm{kV}$. Images were collected on a $4 \mathrm{~K} \times 4 \mathrm{~K} C \mathrm{CD}$ Gatan camera with an effective resolution of $2.8 \AA /$ pixel at specimen level. The EMAN software package was used for analysis. The particles were selected from the electron micrographs using EMAN's Boxer routine. The particles were translationally and rotationally aligned, classified, and averaged without applying symmetry, using EMAN's Refine2d command. The EMAN's multirefine program was used to separate classes of particles based on their size and structure. The dimensions of the class averages generated by EMAN were measured using the ImageJ software (National Institute of Health [NIH], Bethesda, MD, U.S.A.).

\section{Micrococcal nuclease treatment of virions.}

WT or mutant purified viruses $(20 \mu \mathrm{g})$ were diluted 10 -fold with $0.1 \mathrm{M}$ phosphate buffer of $\mathrm{pH} 6.0$ and 7.0 containing 2.5 $\mathrm{mM} \mathrm{CaCl}{ }_{2}$ and were treated with micrococcal nuclease $(1$ gel unit per $\mu$ l) (New England BioLab, Beverly, MA, U.S.A.) at $37^{\circ} \mathrm{C}$ for $0,10,20$, and $30 \mathrm{~min}$. The reactions were terminated by the addition of EGTA to a final concentration of $5 \mathrm{mM}$. After a phenol-chloroform extraction and ethanol precipitation, the RNA was subjected to agarose gel electrophoresis and Northern blot analysis as described above.

\section{ACKNOWLEDGMENTS}

We thank L. Kao for editing, the Indiana University Cereal Killers for their helpful discussions and support during this work, and the Indiana University Mass Spectrometry facility for the use of spectrometers. Funding was provided by National Science Foundation Genome Systems grant MCB0641362 to C. C. Kao and NIH GM081929 for bioimaging to B. Dragnea and C. C. Kao. M. Hema acknowledges the Department of Biotechnology, New Delhi, India for providing DBT long-term Overseas Associateship to perform this work.

\section{LITERATURE CITED}

Ahola, T., and Ahlquist. P. 1999. Putative RNA capping activities encoded by Brome mosaic virus: Methylation and covalent binding of guanylate by replicase protein 1a. J. Virol. 73:10061-10069.

Annamalai, P., and A. L. Rao. 2007. In vivo packaging of Brome mosaic virus RNA3, but not RNAs 1 and 3, is dependent on a cis-acting 3' tRNA-like structure. J. Virol. 81:173-181.

Calhoun, S. L., Speir, J. A., and Rao, A. L. N. 2007. In vivo particle polymorphism results from deletion of a N-terminal peptide molecular switch in brome mosaic virus capsid protein. Virology 364:407-421.

Chen, C., Daniel, M. C., Quinkert, Z. T., De, M., Stein, B., Bowman, V. D., Chipman, P. R., Rotello, V. M., Kao, C. C., and Dragnea, B. 2006. Nanoparticle-templated assembly of viral protein cages. Nano letters 6:611-615.

Chen, J., Noueiry, A., and Ahlquist, P. 2001. Brome mosaic virus protein 1a recruits viral RNA2 to RNA replication through a 5' proximal RNA2 signal. J. Virol. 75:3207-3219.
Choi, Y. G., Grantham, G. L., and Rao, A. L. 2000. Molecular studies on bromovirus capsid protein. Virology 270:377-385.

Diez, J., Ishikawa, M., Kaido, M., and Ahlquist, P. 2000. Identification and characterization of a host protein required for efficient template selection in viral replication. Proc. Natl. Acad. Sci. U.S.A. 97:39133918 .

Dixit, S. K., Goicochea, N. L., Daniel, M. C., Murali, A., Bronstein, L., De, M., Stein, B., Rotello, V. M., Kao, C. C., and Dragnea, B 2006. Quantum dot encapsulation in viral capsids. Nano Lett. 6:1993-1999.

Douglas, T., and Young, M. 1998. Host-guest encapsulation of materials by assembled virus protein cages. Nature 393:152-155.

Fulton, J., Douglas, T., and Young, A. M. 2009. Isolation of viruses from high temperature environments. Methods Mol. Biol. 501:43-54.

Gopinath, K., Dragnea, B., and Kao, C. C. 2005. Interaction between brome mosaic virus proteins and RNAs: Effects on RNA replication, protein expression and RNA stability. J. Virol. 79:14222-14234.

Gopinath, K., and Kao, C. C. 2007. Replication-independent long-distance trafficking by viral RNAs in Nicotiana benthamiana. Plant Cell 19:1179-1191.

Hema, M., and Kao, C. C. 2004. Template sequence near the initiation nucleotide can modulate brome mosaic virus RNA accumulation in plant protoplasts. J. Virol. 78:1169-1180.

Hiebert E., and Bancroft, J. B. 1969. Factors affecting the assembly of some spherical viruses. Virology 39:296-311.

Jennings G. T., and Bachmann, M. F. 2008. The coming of age of viruslike particle vaccines. Biol. Chem. 389:521-536.

Kao, C. C., and Sivakumaran, K. 2000. Brome mosaic virus, good for an RNA virologist's basic needs. Mol. Plant Pathol. 1:91-97.

Kim Y. C., Russell, W. K., Ranjith-Kumar, C. T., Thomson, M., Russell, D. H., and Kao, C. C. 2005. Functional analysis of RNA binding by the hepatitis C virus RNA-dependent RNA polymerase. J. Biol. Chem. 280:38011-38019.

Klug, W. S., Bruinsma, R. F., Michel, J. P., Knobler, C. M., Ivanovska, I. L., Schmidt, C. F., and Wuite, G. J. 2006. Failure of viral shells. Phys. Rev. Lett. 97:228101-228104.

Kroner, P. A., Young, B. M., and Ahlquist, P. 1990. Analysis of the role of Brome mosaic virus 1a protein domains in RNA replication, using linker insertion mutagenesis. J. Virol. 64:6110-6120.

Laemmli, U. K. 1970. Cleavage of structural proteins during the assembly of the head of bacteriophage T4. Nature 227:680-685.

Lucas, R. W., Larson, S. B., and McPherson, A. 2002. The crystallographic structure of Brome mosaic virus. J. Mol. Biol. 317:95-108.

Marsh, L. E., Huntley, C. C., Pogue, G. P., Connell, J. P., and Hall, T. C. 1991. Regulation of (+):(-)-strand asymmetry in replication of brome mosaic virus RNA. Virology 182:76-83.

Michel, J. P., Ivanovska, I. L., Gibbons, M. M., Klug, W. S., Knobler, C. M., Wuite, G. J., and Schmidt, C. F. 2006. Nanoindentation studies of full and empty viral capsids and the effects of capsid protein mutations on elasticity and strength. Proc. Natl. Acad. Sci. U.S.A. 103:6184-6189.

Miller, W. A., Dreher, T. W., and Hall, T. C. 1985. Synthesis of brome mosaic virus subgenomic RNA in vitro by internal initiation on (-)-sense genomic RNA. Nature 313:68-70.

Noueiry, A. O., and Ahlquist, P. 2003. Brome mosaic virus RNA replication: Revealing the role of the host in RNA virus replication. Annu. Rev. Phytopathol. 41:77-98.

Pfeiffer, P., and L. Hirth. 1974. Aggregation states of brome mosaic virus proteins. Virology 61:160-167.

Ranjith-Kumar, C.T., Murali, A., Dong, W., Srisathiyanarayanan, D., Vaughan, R., Ortiz-Alacantara, J., Bhardwaj, K., Li, X., Li, P., and Kao, C. C. 2009. Agonists and antagonists recognition by RIG-I, a cytoplasmic innate immunity receptor. J. Biol. Chem. 284:1155-1165.

Rao, A. L. 2006. Genome packaging by spherical plant RNA viruses. Annu. Rev. Phytopathol. 44:61-87.

Rao, A. L., and Grantham, G. L. 1995. Biological significance of the seven amino terminal basic residues of brome mosaic virus coat protein. Virology 211:42-52.

Sambrook, J., and Russell, D. W. 2001. Molecular Cloning: A Laboratory Manual. 3rd ed. Cold Spring Harbor Laboratory Press, Cold Spring Harbor, NY, U.S.A.

Schwartz, M., Chen, J., Lee, W. M., Janda, M., and Ahlquist, P. 2004. Alternate, virus induced membrane rearrangement support positive-strand RNA virus genome replication. Proc. Natl. Acad. Sci. U.S.A. 101:11263-11268

Siegel, R. W., Adkins, S., and Kao, C. C. 1997. Sequence-specific recognition of a subgenomic promoter by a viral RNA polymerase. Proc. Natl. Acad. Sci. U.S.A. 94:11238-11243.

Speir, J. A., Bothner, B., Qu, C., Willits, D. A., Young, M. J., and Johnson, J. E. 2006. Enhanced local symmetry interactions globally stabilize a mutant virus capsid that maintains infectivity and capsid dynamics. J. Virol. 80:3582-3591. 
Sullivan, M. L., and Ahlquist, P. 1999. A brome mosaic virus intergenic RNA3 replication signal functions with viral replication protein 1a to dramatically stabilize RNA in vivo. J. Virol. 73:2622-2632.

Sun, J., DuFort, C., Daniel, M. C., Murali, A., Chen, C., Gopinath, K., Stein, B., De, M., Rotello, V. M., Holzenburg, A., Kao, C. C., and Dragnea, B. 2007. Core-controlled polymorphism in virus-like particles. Proc. Natl. Acad. Sci. U.S.A. 104:1354-1359.

Yi, G., and Kao, C. 2008. Cis- and trans-acting functions of brome mosaic virus protein 1a in genomic RNA1 replication. J. Virol. 82:30453053 .
Yi, G., Letteney, E., Kim, C.H., and Kao, C. C. 2009a. Brome mosaic virus capsid protein regulates accumulation of viral replication proteins by binding to the replicase assembly RNA element. RNA 15:615-626.

Yi, G., Robert Vaughan, R. C., Ian Yarbrough, I., Dharmaiah, S., and Kao, C. C. 2009 b. RNA binding by the brome mosaic virus capsid protein and the regulation of viral RNA accumulation. J. Mol. Biol. 391:314326.

Zhu, J., Gopinath, K., Murali, A., Yi, G., Hayward, S. D., Zhu, H., and Kao, C. 2007. RNA-binding proteins that inhibit RNA virus infection. Proc. Natl. Acad. Sci. U.S.A. 104:3129-3134. 